\title{
LA MUJER EMPRENDEDORA EN EL TURISMO RURAL: PECULIARIDADES DEL CASO COSTARRICENSE A TRAVÉS DE LA REVISIÓN BIBLIOGRÁFICA
}

\author{
Merlyn Gutiérrez Cruz* \\ Universidad de Alcalá \\ https://orcid.org/0000-0002-3558-1373 \\ María Jesús Such Devesa* \\ Universidad de Alcalá \\ https://orcid.org/0000-0001-9469-3730 \\ Patricia Gabaldón Quiñones** \\ IE Business School \\ https://orcid.org/0000-0002-7443-2661
}

\section{RESUMEN}

Este artículo analiza el fenómeno de la mujer emprendedora en el turismo rural en Costa Rica, enmarcándola en el contexto latinoamericano y en el de las emprendedoras rurales. A partir de una revisión sistemática de la literatura, se define el perfil de las empresarias, sus motivaciones y las barreras que enfrentan. Los resultados ponen de manifiesto las importantes similitudes entre las emprendedoras turísticas rurales costarricenses con el resto de las emprendedoras en Latinoamérica y del mundo. Este estudio contribuye al conocimiento de las emprendedoras dentro del marco del turismo rural, esencial para el desarrollo económico del país.

Palabras clave: mujer emprendedora, turismo rural; Latinoamérica; Costa Rica.

Fecha de recepción: 22 de marzo de 2019

Fecha de aceptación: 14 de octubre de 2019

* Departamento de Economía. Facultad de Ciencias Económicas, Empresariales y Turismo. Universidad de Alcalá. Plaza de la Victoria 2. 28802 Alcalá de Henares. MADRID (España).E-mail: merlyn.gutierrez.cruz@una. cr,mjesus.such@uah.es

** IE Business School. IE University. C/ Castellon de la Plana 8. 28006 MADRID (España). E-mail: patricia. gabaldon@ie.edu 


\title{
The entrepreneurial woman in rural tourism: peculiarities of the Costa Rican case through the literature review
}

\begin{abstract}
This article analyzes the phenomenon of entrepreneurial women in rural tourism in Costa Rica, framed within the Latin-American and rural entrepreneurship context. Using a systematic literature review, the profile of business-women gets defined through their motivations to start their businesses and the barriers they face. The results show the important similarities between Costa Rican rural tourism entrepreneurs and other female entrepreneurs in Latin America and the world. This study contributes to the knowledge of these entrepreneurs within the framework of rural tourism, essential for the economic development of developing countries.
\end{abstract}

Keywords: entrepreneur woman; rural tourism; Latin America; Costa Rica.

\section{INTRODUCCIÓN}

El número de empresas dirigidas por mujeres ha crecido exponencialmente en los últimos años (Brush et al., 2009; Ruiz Navarro et al., 2015), tanto en países en vías de desarrollo (Ascher, 2012; Kelley et al., 2015) como en economías avanzadas (DeMartino y Barbato, 2003; Quader, 2012). El Global Entrepreneurship Monitor (GEM), Reporte de Emprendimiento de Mujeres 2016/2017 reveló que, en el 2016, alrededor de 163 millones de mujeres en 74 economías del mundo, iniciaron o dirigieron nuevos negocios, de las cuales 111 millones tenían negocios establecidos. La actividad empresarial total entre las mujeres se incrementó en un 10\%. (Kelley et al., 2017).

Esto acrecentó el interés de los investigadores hacia el emprendimiento femenino (Zapalska, 1997; DeMartino y Barbato, 2003; Díaz Casero et al., 2010; Ramadani et al., 2015). Sin embargo, la información disponible para Latinoamérica es aún escasa; la mayoría de los estudios se centran en países desarrollados (Traverso Cortés et al., 2014). A este limitado conocimiento sobre la participación de las mujeres en la actividad emprendedora latinoamericana (Heller, 2010; Sistema Económico y Latinoamericano del Caribe [SELA], 2010), se une escasa información a nivel de país. En concreto, las investigaciones centradas en Costa Rica son pocas, a pesar de la importancia del emprendimiento femenino en el país (Adamson Badilla et al., 2016).

Este artículo intenta cubrir este hueco de conocimiento y examina a la mujer emprendedora en el turismo rural en Costa Rica, enmarcándola en el contexto latinoamericano y em el de las emprendedoras rurales.

Datos del Índice Global de Emprendimiento 2018 indican que, Costa Rica es el primer país emprendedor en Centroamérica, sexto en Latinoamérica y número 56 a nivel mundial (Ács et al., 2017). A su vez, ofrece condiciones favorables para el avance de las mujeres como líderes, profesionales, emprendedoras y contribuyentes de la fuerza laboral; según el índice de mujeres emprendedoras de Mastercard (2018), Costa Rica obtiene una valoración 
global de 65\%, ubicándose en el puesto 20 de los 57 países analizados. Asimismo, en este índice se destaca que un $21,6 \%$ de las mujeres costarricenses es propietaria de negocios y la proporción de mujeres en edad de trabajar que participan en actividades empresariales de etapa temprana es de un 37\% (Mastercard, 2018).

Con el fin de disponer de una perspectiva holística del fenómeno de las emprendedoras turísticas rurales, el artículo realiza una revisión sistemática de la literatura y trabajos disponibles en el campo. A través de esta revisión se pone de manifiesto la idea de que estas emprendedoras comparten muchos de los rasgos de sus iguales en otros países (mediana edad, casadas y con hijos, y operan microempresas), así como la necesidad de mejorar su calidad de vida como objetivo para crear sus empresas. Todas ellas se enfrentan a obstáculos como la estacionalidad del turismo y los roles de género tradicionales.

La investigación se estructura de la siguiente manera. Primero, se exponen los elementos característicos de la mujer emprendedora; seguidamente, se indaga el papel de las emprendedoras en el turismo. Finalmente, se establecen las características de la mujer empresaria en el turismo rural. En los diferentes apartados, la información se desagrega a tres niveles geográficos: global, Latinoamérica y el Caribe y Costa Rica.

\section{METODOLOGÍA}

Este estudio se basa en la revisión sistemática de una selección de artículos y otras fuentes secundarias. Las palabras claves utilizadas en la búsqueda fueron: mujer emprendedora, emprendimiento femenino, perfil, motivaciones, barreras, turismo, turismo rural, Latinoamérica, Costa Rica; y su equivalente en inglés. Se emplearon las bases de datos Science Direct, Scielo, Redalyc, Scopus, EBSCO, Web of Science, Emerald, Jstor y Teseo. Asimismo, se incluyeron en la revisión, artículos citados en los documentos consultados y que se consideraron importantes para la investigación.

En total se revisaron 91 estudios académicos empíricos e informes de organismos gubernamentales y privados, con fechas entre 1993 a 2018, que abordaran el tema de la mujer emprendedora y de emprendimientos en turismo rural.

\section{ELEMENTOS CARACTERÍSTICOS DE LA MUJER EMPRENDEDORA EN EL MUNDO}

Las mujeres contribuyen al crecimiento de los países como emprendedoras. De acuerdo con datos del Reporte GEM de Emprendimiento de Mujeres 2016/2017, la tasa de actividad emprendedora (TEA) femenina ha aumentado en un 10\%, en comparación con el informe anterior. La región que tiene las expectativas de crecimiento promedio más altas entre las mujeres, con un 37\%, es Oriente Medio y África del Norte (MENA) (Kelley et al., 2017).

Las emprendedoras se han caracterizado por ser adaptables, por su conciencia social (Buttner, 1993) y la combinación de objetivos sociales y económicos en sus empresas (McClelland et al., 2005). Los principales factores que influyen en el emprendimiento 
femenino son "la motivación individual, la estructura familiar, la educación, la demografía, el desempleo y los entornos sociales y económicos" (Ascher, 2012, p.110).

De acuerdo con la Organización para la Cooperación y el Desarrollo Económicos (OCDE) (2018), contrario a los hombres, para muchas mujeres, ganar más dinero no constituye la principal motivación cuando crean un negocio, sino que en muchos casos son impulsadas por la búsqueda de un interés o un pasatiempo - es el caso de países como Israel, Suecia, Indonesia y Hungría, entre otros.

Estudios realizados en Polonia, Sri Lanka, Australia, Arabia Saudita y Kosovo, señalan que las mujeres emprenden entre los 30 y 50 años; poseen educación superior (Zapalska, 1997; Ayadurai y Sohail, 2006; Still y Walker, 2006; Zamberi Ahmad, 2011; Ramadani et al., 2015) y utilizan los ahorros personales para empezar sus empresas (Still y Walker, 2006; Zamberi Ahmad, 2011). Éstas poseen microempresas, ubicadas principalmente en el sector servicios (Still y Walker, 2006; Zamberi Ahmad, 2011; Ramadani et al., 2015) y son propietarias únicas de sus negocios (Still y Walker, 2006; Zamberi Ahmad, 2011).

No existe una motivación principal que estimule a las mujeres a emprender, pues las razones son variadas y dependen del apoyo familiar, de la actitud hacia el emprendimiento y de las percepciones sociales (Ascher, 2012). Asimismo, depende de la situación económica a la que se enfrenten las mujeres y de las características del ecosistema en que se desarrollan. En los países en desarrollo, muchas mujeres que se convierten en empresarias se caracterizan por ser analfabetas y vivir en comunidades pobres, esta condición es la que las impulsa a buscar opciones para generar ingresos, que indirectamente beneficia su entorno al generar empleos (Ascher, 2012).

Según las investigaciones disponibles, en países como Polonia, Sri Lanka, Australia y Arabia Saudita, las mujeres crean sus empresas motivadas por el deseo de mejorar su calidad de vida (Ayadurai y Sohail, 2006), la búsqueda de independencia, flexibilidad, satisfacción laboral y para generar ingresos (Zapalska, 1997; Still y Walker, 2006; Zamberi Ahmad, 2011).

Asimismo, estudios sobre las empresarias de Australia, Arabia Saudita y Kosovo señalan que éstas se enfrentan a barreras comunes: dificultad para acceder a financiamiento, carencia de experiencia y capacitación, falta de confianza, excesivas regulaciones gubernamentales (Zamberi Ahmad, 2011; Ramadani et al., 2015) y problemas en la etapa inicial para asesorarse y redactar un plan de negocios (Still y Walker, 2006).

\subsection{Emprendimiento femenino en América Latina y el Caribe}

América Latina es la región del mundo con los niveles de intención empresarial más altos, únicamente superada por África (Kelley et al., 2015). El promedio para la actividad empresarial total femenina (edad 18 a 64) de Latinoamérica y el Caribe es de $17 \%$. No obstante, la región también tiene las expectativas de crecimiento femenino promedio más bajas (Kelley et al., 2017).

La región presenta retos en cuanto a la mejora en las regulaciones y facilidades necesarias para hacer negocios, ya que los países latinoamericanos que ocupan las mejores posiciones entre las 190 economías del "Doing Business" index desarrollado por el Banco Mundial son México (54), Chile (56), Puerto Rico (64) y Colombia (65). Costa Rica se 
ubica en la posición 67, quinta a nivel latinoamericano y primera a nivel centroamericano (Banco Mundial, 2018).

La tasa de desempleo de las mujeres en América Latina y El Caribe, en el 2016, fue de $10,9 \%$. Belice $(15,6 \%)$ es el país que presenta el mayor porcentaje, seguido de Brasil (14,78\%) y Bahamas (14,5\%). Costa Rica al igual que Colombia se ubican en la quinta posición con una tasa de $11,5 \%$ (Comisión Económica para América Latina y el Caribe [CEPAL], 2017).

Las mujeres indígenas latinoamericanas enfrentan mayores dificultades que afectan su vida familiar y comunitaria, debido a los problemas de exclusión económica y social que enfrentan, así como las condiciones de pobreza en que viven (Galindo et al., 2016). Un $43 \%$ de los hogares indígenas de la región viven bajo el umbral de la pobreza y un $24 \%$ se encuentran en condiciones de pobreza extrema (Banco Mundial, 2015).

Las mujeres latinas se convierten en empresarias en la búsqueda de flexibilidad e independencia dada la falta de oportunidades laborales y la necesidad de llevar un sustento a sus hogares (Organismo Alemán de Cooperación Técnica [GTZ] et al., 2010; Heller, 2010; SELA, 2010). De forma similar, en los pueblos indígenas, las mujeres emprenden por el deseo de integrar la cultura con sus actividades económicas (Ratten y Dana, 2017) y al mismo tiempo evitar el despoblamiento de sus reservas (Galindo et al., 2016).

Las investigaciones existentes indican que las mujeres emprendedoras en América Latina se caracterizan por ser de mediana edad, estar casadas, tener hijos y familiares a cargo (Heller, 2010; Traverso Cortés et al., 2014), tener un nivel educativo bajo, emprender por necesidad (SELA, 2010; Traverso Cortés et al., 2014), poseer micro y pequeñas empresas (GTZ et al., 2010; Heller, 2010; SELA, 2010; Traverso Cortés et al., 2014), y operar en el sector comercio (GTZ et al., 2010), manufactura (GTZ et al., 2010; Traverso Cortés et al., 2014) y servicios (Heller, 2010; SELA, 2010). En el caso de las mujeres indígenas, éstas poseen limitado a acceso a la educación (Hall y Patrinos, 2005) y generalmente operan en el sector informal en actividades artesanales tradicionales y en servicios (Jaspers y Montaño, 2013).

Las micro, pequeñas y medianas empresas (mipymes) ${ }^{1}$ femeninas de la región enfrentan obstáculos como dificultad de acceso a fuentes de financiamiento, a tecnología, a información y a redes de comercialización (GTZ et al., 2010; Heller, 2010; SELA, 2010). Estas mujeres presentan carencias en su formación y experiencia empresarial (Heller, 2010), poseen escaso capital y se les dificulta conciliar su vida familiar y empresarial (SELA, 2010). Estas emprendedoras tienen un acceso limitado a la propiedad de tierra y/o sus hogares, y la falta de títulos de propiedad de activos inmuebles que sirvan de garantía, les limita el acceso a créditos (GTZ et al., 2010). De acuerdo con Padilla y Ciruela (2018), "las mujeres empresarias indígenas en América Latina enfrentan varios problemas económicos y desafíos sociales al desarrollar sus actividades. La sociedad

1 Si bien no hay un concepto único para las mipymes a nivel latinoamericano, en Costa Rica, se define como "toda unidad productiva de carácter permanente que disponga de los recursos humanos, los maneje y opere, bajo las figuras de persona física o de persona jurídica, en actividades industriales, comerciales, de servicios o agropecuarias que desarrollen actividades de agricultura orgánica" (Asamblea Legislativa de la República de Costa Rica, 2002). 
en general, los valores de la comunidad y los rasgos individuales se han señalado como los principales factores que afectan su desarrollo" (p. 159).

La mayoría de los países latinoamericanos ofrecen instrumentos y servicios de apoyo para las empresarias en áreas como creación de empresas, acceso a financiamiento, asistencia técnica, capacitación, innovación, mejoras de gestión, internacionalización, articulación productiva y compras públicas (Corporación Andina de Fomento [CAF] y Banco de Desarrollo de América Latina, 2013).

\subsection{Emprendimiento femenino en Costa Rica}

De acuerdo con la Encuesta Nacional de Hogares Productores del 2015, un 34,9\% del total de personas emprendedoras son mujeres, mientras que un $65,1 \%$ son hombres (Instituto Nacional de Estadística y Censos [INEC], 2016). Asimismo, según el vigésimo segundo informe del Estado de la Nación, el 56\% de los emprendimientos dirigidos por mujeres operan totalmente en la informalidad, en contraposición con un $29 \%$ encabezado por hombres (Programa Estado de la Nación en Desarrollo Humano Sostenible, 2016).

Los requisitos para que una empresa opere legalmente en Costa Rica son inscribirse ante el Registro Mercantil o Registro de la Propiedad (sólo si se trata de un emprendimiento con personería jurídica), contar con permiso de funcionamiento del Ministerio de Salud, asegurar a sus empleados en la Caja Costarricense del Seguro Social (CCSS) o asegurarse como trabajador independiente, obtener la póliza de riesgos del trabajo en el Instituto Nacional de Seguros (INS) u otra aseguradora, solicitar la patente municipal e inscribirse en Tributación Directa como contribuyente (Ministerio de Economía, Industria y Comercio [MEIC] y Organización Internacional del Trabajo [OIT], 2019). Debido a la complejidad y el costo de los trámites, algunos emprendimientos operan en la informalidad.

Las empresarias costarricenses se caracterizan por tener entre 35 y 49 años, poseer estudios universitarios, financiar con ingresos propios, operar microempresas, pertenecer al sector servicios, iniciar con apoyo del cónyuge, padres u otros familiares y depender de las ganancias de la empresa (Brenes Bonilla y Bermúdez Mesén, 2013; Leiva Bonilla, 2013). Para fortalecerse se organizan en asociaciones, y esto les permite recibir apoyo de instituciones públicas y privadas (González Calvo y Espinoza Herrera, 2010).

En Costa Rica, la necesidad de independencia, de mejora de la calidad de vida, de apoyar económicamente a la familia, el deseo de superación, y de poseer un negocio, motiva a las mujeres para emprender (Brenes Bonilla y Bermúdez Mesén, 2013).

Como en el resto de Latinoamérica, las dificultades a las que se enfrentan son el acceso a financiamiento, la falta de un local comercial para desarrollar la actividad (González Calvo y Espinoza Herrera, 2010) y la limitada experiencia y conocimiento empresarial (Brenes Bonilla y Bermúdez Mesén, 2013). 


\section{PAPEL DE LA MUJER EMPRENDEDORA EN EL TURISMO}

El turismo es un fenómeno mundial que fomenta el crecimiento económico, la reducción de la pobreza y el desarrollo comunitario. En el 2017, las llegadas de turistas internacionales en el mundo fueron de 1326 millones de personas y los ingresos generados equivalen a USD1340 billones, esto representa un crecimiento anual del 7\% y 5\% respectivamente. Las regiones que presentaron el mayor crecimiento en llegadas fueron África $(8,6 \%)$ y Europa $(8,4 \%)$ (Organización Mundial del Turismo [OMT], 2018). En 2017, la contribución total del sector fue de USD8272,3 billones (10,4\% del PIB mundial) y generó un 9,9\% del empleo total (313 millones de empleos directos, indirectos e inducidos) (World Travel \& Tourism Council [WTTC], 2018a).

En las Américas, la región que creció más fue América del Sur $(8,3 \%)$, seguida de América Central (4,7\%). Argentina, Brasil y Chile son los países de Sudamérica que lideraron las llegadas de turistas. En Centroamérica fueron Costa Rica, Panamá y Nicaragua. Mientras que, en el Caribe, destacan República Dominicana y Puerto Rico. México se encuentra sexto dentro del listado de principales destinos de llegadas turísticas internacionales. (OMT, 2018). El aporte total del turismo al PIB Mundial, en las Américas, fue de USD2199,5bn (8,3\% del PIB) y generó 9,4\% del total de empleos (42 millones de empleos), en 2017 (WTTC, 2018b). Por su parte, la contribución total al PIB en Costa Rica fue de USD7514,7 millones y creó $12,5 \%$ del total de empleos (254500 trabajos) (WTTC, 2018c).

Según el Índice de Competitividad en Viajes y Turismo de 2017, México (22), Brasil (27), Panamá (35), Costa Rica (38), Chile (48), Argentina (50) y Perú (51) destacan como los países latinoamericanos con los mejores puestos en el ranking mundial. Sus principales retos son la mejora en la seguridad y protección, crear entornos más propicios para las empresas y desarrollar su infraestructura para mejorar la conectividad (Foro Económico Mundial, 2017).

La hostelería y el turismo en general, es una de las vías que permiten promover el empoderamiento de las mujeres, al establecer negocios con los que aprovechan las habilidades que poseen. Esto les permite sentirse más seguras, ejercer su autonomía, ser económicamente independientes, disponer de un estatus más elevado, ganarse el respeto de la comunidad, y tener representación en grupos comunitarios (OMT y ONU Mujeres, 2013).

Investigaciones realizadas en Uganda, Bali (Indonesia), KwaZulu-Natal (Sudáfrica) y Maldivas, señalan que las mujeres emprendedoras en turismo tienen entre 31 y 35 años, están casadas, con hijos, poseen niveles educativos de secundaria y universidad (Katongole et al., 2013; Tshabalala y Ezeuduji, 2016; Tajeddini et al., 2017), tienen entre 3 y 19 empleados, consultan a su familia para tomar las decisiones (Tajeddini et al., 2017) y utilizaron ahorros personales para iniciar la actividad (Tshabalala y Ezeuduji, 2016). Las motivaciones que impulsan a emprender a estas mujeres son tanto la necesidad como la oportunidad, así como la flexibilidad para combinar trabajo y familia (Alm y Johansson, 2011; Tajeddini et al., 2017), obtener respeto de parte de sus parejas y de la comunidad, mejorar su autoestima, tener mayor confianza, y conseguir prestigio al apoyar en los gastos del hogar (OMT y ONU Mujeres, 2013; Tajeddini et al., 2017). 
Las emprendedoras turísticas de Maldivas, KwaZulu-Natal (Sudáfrica) y Bali (Indonesia), se enfrentan a similares problemas que el resto de las emprendedoras, como la falta de capital financiero, el desconocimiento sobre fuentes de financiación (Alm y Johansson, 2011; OMT y ONU Mujeres, 2013; Tshabalala y Ezeuduji, 2016; Tajeddini et al., 2017), y otros específicos como la inexperiencia para establecer redes comerciales y atraer turistas, la venta de artesanías a precios bajos (Tshabalala y Ezeuduji, 2016), la incapacidad de satisfacer, en volumen y en calidad, la demanda de productos de los complejos turísticos (Alm y Johansson, 2011) y la dificultad para conciliar familia y trabajo por no contar con el apoyo de su pareja (Tajeddini et al., 2017).

Un elemento peculiar del sector turístico es que estas mujeres empresarias se encuentran organizadas a través de cooperativas, sindicatos o asociaciones, lo que facilita el intercambio de conocimientos, la capacitación, la comunicación, mejora su presencia en el mercado y favorece el apoyo de organizaciones no gubernamentales (ONGs) (Alm y Johansson, 2011; OMT y ONU Mujeres, 2013; Tshabalala y Ezeuduji, 2016; OMT y Huzhou City, 2017).

Dentro de las ventajas que tiene el turismo para las mujeres están su facilidad para ingresar en el mercado de trabajo, la oportunidad de establecer negocios en los propios hogares, el poder trabajar a tiempo parcial o por turnos y las mejoras a la infraestructura para las comunidades donde se desarrolla (OMT y ONU Mujeres, 2013).

\subsection{Emprendedoras turísticas en Latinoamérica y el Caribe}

Según la OMT y ONU Mujeres (2013), “América Latina es la región con la proporción más alta de trabajadoras por cuenta propia en el sector de hoteles y restaurantes. En la mayoría de los países centroamericanos la cantidad de mujeres que trabajan por cuenta propia en el sector de hoteles y restaurantes es el doble que en otros sectores" (op. cit. p.42).

Las emprendedoras turísticas latinoamericanas comparten características con las del resto del mundo. Según estudios en Huatulco (México), Brasil y Ecuador, éstas se caracterizan por tener entre 34 a 49 años, estar casadas, tener hijos, poseer educación superior, desempeñarse en actividades de hostelería y agencias de viajes (Fernández Aldecua y Martínez Barón, 2010; Costa et al., 2015; Sarango Lalangui et al., 2016), ser propietarias de empresas pequeñas (Ferguson, 2010), poseer de 1 a 13 empleados, utilizar sus ahorros para iniciar (Fernández Aldecua y Martínez Barón, 2010) recibir capacitación en temas turísticos y unirse en asociaciones o cooperativas para fortalecerse y comercializar sus productos (Costa et al., 2015).

En la misma línea, su motivación para emprender es el deseo de poseer su propio negocio y obtener independencia (Ferguson, 2010), búsqueda de satisfacción personal y profesional, equilibrar trabajo y familia (Fernández Aldecua y Martínez Barón, 2010; Costa et al., 2016) y la necesidad (Fernández Aldecua y Martínez Barón, 2010; Sarango Lalangui et al., 2016). De nuevo, estas mujeres emprendedoras se enfrentan a obstáculos como la ausencia de títulos de propiedad -las empresas están a nombre de sus parejas- (Ferguson, 2010), miedo al fracaso (Costa et al., 2016; Sarango Lalangui et al, 2016), falta de confianza, operan en la informalidad por lo complicado y costoso de los 
trámites y leyes laborales (Ferguson, 2010; Costa et al., 2016), falta de capacitación y dificultad para acceder a financiación, crear redes comerciales o conciliar trabajo y familia (Costa et al., 2016).

\subsection{Emprendedoras turísticas en Costa Rica}

En Costa Rica, el turismo es una de las principales actividades generadoras de divisas. Desde los años 80, el país enfocó su desarrollo turístico en el ecoturismo y ha evolucionado hacia un modelo de gestión sostenible, posicionándolo como destino líder a nivel regional y mundial (Instituto Costarricense de Turismo [ICT], 2015). Se ha promovido el diseño de productos turísticos únicos que combinen experiencias naturales y culturales, buscando la distribución equitativa de los beneficios y la participación activa de las comunidades locales donde se ubican los atractivos (ICT, 2015).

En el año 2016, la actividad turística costarricense generó 83.768 empleos directos femeninos y 59.533 por servicios conexos, sumados representan un 5,5\% del empleo total del país. De estos, un 20,4\% equivalen a trabajadoras por cuenta propia (BCCR, 2018).

A pesar de la importancia del fenómeno del emprendimiento femenino en el turismo, existe escasa información de las características de las emprendedoras turísticas costarricenses. Bonilla Moya (2002) señala que se caracterizan por tener una edad promedio de 37 años, poseer educación primaria completa, estar casadas, tener hijos, trabajar en granjas o como amas de casa, y depender económicamente de su padre o esposo. La principal motivación para emprender es la búsqueda de independencia económica.

Como novedad, en este caso, la motivación para la creación de empresas y empoderamiento en el sector turístico es percibido no solo como generador de ingresos, sino también como una forma de entretenimiento, porque se reúnen con otras artesanas para trabajar y capacitarse, lo que les da autonomía, reconocimiento y al mismo tiempo les permite mejorar sus vidas (Bonilla Moya, 2002). Los ingresos obtenidos les ha permitido diversificar sus actividades de ocio, además de darles más confianza para tomar decisiones personales y del hogar (Bonilla Moya, 2002.; Ferguson, 2010).

Igual que en otros sectores, los principales problemas a los que se enfrentan es la falta de confianza al iniciar, la informalidad y la carencia de títulos de propiedad (Ferguson, 2010).

\section{MUJER EMPRENDEDORA EN EL TURISMO RURAL}

El empoderamiento de las mujeres y el fin de la pobreza, son objetivos de la Agenda 2030 para el Desarrollo Sostenible (ODS). El fomento de un turismo sostenible en el medio rural, entendido como el aprovechamiento respetuoso de los recursos naturales, culturales y sociales de una comunidad, al tiempo que se generan beneficios económicos (Saarinen, 2006), puede contribuir a dinamizar las economías locales y a alcanzar estas metas.

El turismo rural nace como una actividad económica complementaria a las tradicionales (Garin Contreras, 2015); que se práctica en espacios rurales, impulsa el desarrollo socioeconómico, cultural y ambiental de las comunidades, y genera empleo para jóvenes, mujeres y adultos mayores (Pérez, 2010; Talón-Ballestero et al., 2014). Es un 
segmento de mercado en desarrollo y con gran potencial. Este sector capta un $3 \%$ de todos los turistas internacionales y su tasa de crecimiento anual es de aproximadamente un $6 \%$ (OMT, 2002). Este incremento de la demanda ha incentivado la participación femenina en iniciativas rurales.

Las mujeres emprendedoras en Placencia (Belice), Monteverde (Costa Rica) Copán (Guatemala), Cuandixia (China), Perú y Suecia se benefician del turismo rural por la generación de empleos, mejora del nivel de vida de las familias, integración de la comunidad, conservación de la cultura, aumento de la autoestima (Ling et al., 2013; Ypeij, 2013), reactivación de la economía local (Ling et al., 2013; Pettersson y Heldt Cassel, 2014) e independencia económica (Ferguson, 2010; Ypeij, 2013; Pettersson y Heldt Cassel, 2014).

Estudios empíricos en España, Virginia (EE. UU), Suecia y Grecia, determinaron que las mujeres emprendedoras dedicadas al turismo rural son mayores de 36 años, están casadas, tienen hijos (Morales Hernández et al., 2016.; Koutsou et al., 2009; TalónBallestero et al., 2014), utilizan financiación ajena o fondos propios (Talón-Ballestero et al., 2014) y realizaron estudios medios y superiores (Koutsou et al., 2009; Flores y De la O Barroso, 2011). Estas mujeres dependen únicamente de los ingresos procedentes de su emprendimiento, y aunque son microempresas (McGehee et al., 2007; Koutsou et al., 2009; Flores y Barroso, 2011; Talón-Ballestero et al., 2014), se capacitaron en temas turísticos y de servicio al cliente (Flores y Barroso, 2011), ya que en su mayoría antes de emprender no estaban relacionadas con el sector agrícola (Pettersson y Heldt Cassel, 2014).

Estas mujeres emprenden ante la necesidad de poseer un negocio propio (Flores y Barroso, 2011), buscar independencia (McGehee et al., 2007; Flores y Barroso, 2011), combinar trabajo con cuido de sus hijos y cambiar sus vidas, pero también desarrollar ideas y mantener el paisaje rural (Pettersson y Heldt Cassel, 2014).

Los emprendimientos rurales femeninos se enfrentan a obstáculos específicos de esta actividad como la estacionalidad (Morales Hernández et al., 2016.; Ferguson, 2010; Pettersson y Heldt Cassel, 2014). A pesar de las dificultades, las mujeres emprendedoras disfrutan de las actividades que desempeñan en el turismo rural (Ling et al., 2013). En ocasiones, las empresarias constituyen sus negocios en cooperativas, lo que les permite colaborar y fortalecerse (Flores y Barroso, 2011; OMT y ONU Mujeres, 2013).

\subsection{Emprendedoras turísticas rurales en Latinoamérica y el Caribe}

En los últimos veinte años, el empoderamiento de las mujeres en América Latina ha aumentado (ONU Mujeres, 2017). No obstante, aún existen desigualdades, en especial, en las áreas rurales, que son las más afectadas por la pobreza. Datos de la CEPAL (2018), estiman que, en la región, la pobreza rural y la pobreza extrema rural femeninas alcanzaron un $43,5 \%$ y un $24,9 \%$, en 2014 . Porcentajes bastante altos comparados con zonas urbanas donde las tasas de pobreza y pobreza extrema fueron de $28,9 \%$ y $10,9 \%$ respectivamente. 
Tabla 1

MUJERES RURALES EN LATINOAMÉRICA Y EL CARIBE

\begin{tabular}{lcccccc}
\hline \multicolumn{1}{c}{ País } & $\begin{array}{c}\text { Pobreza } \\
\text { extrema } \\
\text { rural }\end{array}$ & $\begin{array}{c}\text { Pobreza } \\
\text { rural }\end{array}$ & $\begin{array}{c}\text { PEA (más } \\
\text { de 15 años) }\end{array}$ & $\begin{array}{c}\text { Sin ingresos } \\
\text { propios (más } \\
\text { de 15 años) }\end{array}$ & Empleadoras & $\begin{array}{c}\text { Cuenta } \\
\text { propia }\end{array}$ \\
\hline Brasil & 11,7 & 29,5 & 55,0 & 27,8 & 0,8 & 47,9 \\
Colombia & 19,2 & 43,2 & 44,2 & 35,2 & 2,0 & 51,3 \\
Costa Rica & 11,4 & 22,7 & 35,8 & 46,4 & 2,7 & 20,3 \\
Ecuador & 11,3 & 27,6 & 51,6 & 37,0 & 1,4 & 37,6 \\
El Salvador & 17,5 & 49,3 & 35,2 & 50,7 & 2,3 & 41,3 \\
Guatemala & 58,3 & 77,1 & 32,0 & 59,2 & 0,7 & 37,2 \\
México & 23,0 & 45,1 & 43,8 & 27,0 & 10,3 & 24,8 \\
Panamá & 28,6 & 41,5 & 42,8 & 34,2 & 1,0 & 35,9 \\
Paraguay & 32,3 & 51,7 & 50,6 & 38,7 & 2,5 & 54,2 \\
Perú & 14,6 & 46,9 & 72,2 & 28,7 & 1,8 & 38,8 \\
República & 25,4 & 47,5 & 34,0 & 33,6 & 1,0 & 32,0 \\
Dominicana & & 2,5 & 54,2 & 18,2 & 6,1 & 29,0 \\
Uruguay & 1,1 & 2,5 & & & \\
\hline
\end{tabular}

Fuente: CEPAL, 2018. Comisión Económica para América Latina y el Caribe: Sobre la base de encuestas de hogares de los países. Banco de Datos de Encuestas de Hogares (BADEHOG).

De acuerdo con la información expuesta en la tabla 1, Uruguay es el país que presenta las estadísticas más favorables para la mujer rural. Tiene las tasas más bajas de pobreza extrema rural, pobreza rural y mujeres sin ingresos propios, y muestra un porcentaje alto de población femenina económicamente activa y de empleadoras. En el extremo opuesto está Guatemala, que presenta los datos más desfavorables. En el caso de Costa Rica, a pesar de estar entre los países de la región con menores tasas de pobreza rural y pobreza extrema rural; la participación económica de la mujer rural en edad productiva es baja y tiene un alto porcentaje de mujeres sin ingresos propios. Por otra parte, se puede observar que la proporción de trabajadoras por cuenta propia es mayor que la de empleadoras. Los países que destacan por su alto porcentaje de empleadoras son México, Uruguay y Costa Rica; y por el número de trabajadoras por cuenta propia son Paraguay, Colombia y Brasil.

Las cifras ponen de manifiesto la necesidad de que los gobiernos de la región garanticen la efectividad de las políticas públicas de apoyo al emprendimiento femenino que contribuyan a disminuir la pobreza y diversificar la actividad no agrícola en las zonas rurales, a través de la formación, la capacitación y el empleo para las mujeres, para mejorar la situación actual de las mujeres latinas. Una opción viable es el turismo rural sostenible, que genera aportes significativos a las economías rurales en Latinoamérica por su capacidad de crear oportunidades de negocio a sus pobladores (Picón Cruz y Hernández Ulate, 2014) a partir de sus actividades productivas diarias, preservando la cultura y el entorno 
natural. En especial, se brinda la posibilidad de desarrollo laboral para mujeres y jóvenes quienes se convierten en emprendedores (OMT, 2003).

Según la OMT (2003), la heterogeneidad que presentan las áreas rurales en Latinoamérica, más que competir les permite complementarse para ofrecer variedad de productos que reflejan sus estilos de vida, que va desde pueblos indígenas en México, hasta poblaciones descendientes de europeos en Uruguay y Argentina. A continuación, se presenta una tabla comparativa de la situación del turismo rural en algunos países latinoamericanos.

Tabla 2

SITUACIÓN DEL TURISMO RURAL EN PAÍSES LATINOAMERICANOS

\begin{tabular}{|c|c|c|c|c|c|c|}
\hline País & Origen & $\begin{array}{c}\text { Cantidad } \\
\text { de } \\
\text { negocios }\end{array}$ & $\begin{array}{c}\text { Tamaño } \\
\text { de los } \\
\text { negocios }\end{array}$ & $\begin{array}{l}\text { Actividad más } \\
\text { representativa }\end{array}$ & $\begin{array}{c}\text { Forma de } \\
\text { comercializar }\end{array}$ & $\begin{array}{c}\text { Áreas de apoyo } \\
\text { del sector } \\
\text { público }\end{array}$ \\
\hline Argentina & 1973 & 870 & $\begin{array}{l}\text { Todos los } \\
\text { tamaños }\end{array}$ & $\begin{array}{l}\text { Vinculadas al } \\
\text { caballo y la } \\
\text { gastronomía }\end{array}$ & $\begin{array}{l}\text { Propietarios, } \\
\text { agencias } \\
\text { de viajes y } \\
\text { asociaciones }\end{array}$ & $\begin{array}{l}\text { Promoción del } \\
\text { producto } \\
\text { Programas } \\
\text { específicos } \\
\text { Capacitación }\end{array}$ \\
\hline Brasil & 1986 & 350 & $\begin{array}{l}\text { Mayoría } \\
\text { medianos y } \\
\text { grandes }\end{array}$ & $\begin{array}{l}\text { Haciendas (son } \\
\text { las menos, } \\
\text { pero las más } \\
\text { buscadas) }\end{array}$ & Propietarios & $\begin{array}{l}\text { Financiamiento } \\
\text { Apoyo para la } \\
\text { actividad a través } \\
\text { de Agencias de } \\
\text { desarrollo }\end{array}$ \\
\hline Chile & 1995 & 450 & $\begin{array}{l}\text { Mayoría } \\
\text { pequeños }\end{array}$ & $\begin{array}{l}\text { Labores de } \\
\text { campo o } \\
\text { agropecuarias } \\
\text { y gastronomía } \\
\text { típica }\end{array}$ & $\begin{array}{l}\text { Asociaciones } \\
\text { y propietarios } \\
\text { con apoyo del } \\
\text { gobierno }\end{array}$ & $\begin{array}{l}\text { Promoción del } \\
\text { producto } \\
\text { Programas } \\
\text { específicos } \\
\text { Capacitación } \\
\text { Financiamiento } \\
\text { Subsidio a } \\
\text { inversiones } \\
\text { en zonas con } \\
\text { potencial }\end{array}$ \\
\hline Costa Rica & 1990 & 70 & $\begin{array}{c}\text { Pequeños y } \\
\text { medianos }\end{array}$ & $\begin{array}{l}\text { Gastronomía } \\
\text { típica, } \\
\text { observación de } \\
\text { aves, senderos } \\
\text { naturales, pesca, } \\
\text { cabalgatas y } \\
\text { visita a fincas } \\
\text { agrarias }\end{array}$ & $\begin{array}{l}\text { Tour } \\
\text { operadores } \\
\text { y agencias } \\
\text { de viajes, } \\
\text { operadores } \\
\text { especializados } \\
\text { en TR }\end{array}$ & $\begin{array}{l}\text { Promoción del } \\
\text { producto } \\
\text { Programas } \\
\text { específicos } \\
\text { Capacitación }\end{array}$ \\
\hline México & 1988 & 200 & $\begin{array}{l}\text { Haciendas } \\
\text { tienen } \\
\text { cascos } \\
\text { grandes y } \\
\text { ranchos } \\
\text { grandes }\end{array}$ & $\begin{array}{l}\text { Convivencia con } \\
\text { la comunidad } \\
\text { y atractivos } \\
\text { naturales }\end{array}$ & $\begin{array}{l}\text { Propietarios, } \\
\text { web, } \\
\text { asociaciones } \\
\text { y agencias de } \\
\text { viajes }\end{array}$ & $\begin{array}{l}\text { Promoción del } \\
\text { producto } \\
\text { Programas } \\
\text { específicos } \\
\text { Capacitación } \\
\text { Financiamiento }\end{array}$ \\
\hline
\end{tabular}




\begin{tabular}{|c|c|c|c|c|c|c|}
\hline País & Origen & $\begin{array}{c}\text { Cantidad } \\
\text { de } \\
\text { negocios } \\
\end{array}$ & $\begin{array}{c}\text { Tamaño } \\
\text { de los } \\
\text { negocios }\end{array}$ & $\begin{array}{l}\text { Actividad más } \\
\text { representativa }\end{array}$ & $\begin{array}{c}\text { Forma de } \\
\text { comercializar }\end{array}$ & $\begin{array}{c}\text { Áreas de apoyo } \\
\text { del sector } \\
\text { público }\end{array}$ \\
\hline Nicaragua & 1970 & SD & $\begin{array}{c}\text { Pequeños y } \\
\text { medianos }\end{array}$ & $\begin{array}{l}\text { Parques } \\
\text { Naturales }\end{array}$ & $\begin{array}{l}\text { Propietarios, } \\
\text { web y agencias } \\
\text { de viajes }\end{array}$ & $\begin{array}{l}\text { Promoción del } \\
\text { producto } \\
\text { Programas } \\
\text { específicos } \\
\text { Capacitación }\end{array}$ \\
\hline Panamá & 1970 & 180 & $\begin{array}{l}\text { Mayoría } \\
\text { medianos }\end{array}$ & Folclore & $\begin{array}{l}\text { Propietarios, } \\
\text { agencias } \\
\text { de viajes y } \\
\text { asociaciones }\end{array}$ & $\begin{array}{l}\text { Financiamiento } \\
\text { Promoción del } \\
\text { producto } \\
\text { Programas } \\
\text { específicos } \\
\text { Capacitación }\end{array}$ \\
\hline Paraguay & 1997 & 25 & $\begin{array}{l}\text { Mayoría } \\
\text { medianos }\end{array}$ & $\begin{array}{l}\text { Tareas Rurales } \\
\text { (ordeñe, } \\
\text { marcación, etc.) }\end{array}$ & $\begin{array}{l}\text { Propietarios } \\
\text { y central de } \\
\text { reservas de } \\
\text { asociación }\end{array}$ & $\begin{array}{l}\text { Promoción del } \\
\text { producto } \\
\text { Capacitación }\end{array}$ \\
\hline $\begin{array}{l}\text { República } \\
\text { Dominicana }\end{array}$ & 1997 & 110 & $\begin{array}{l}\text { Mayoría } \\
\text { pequeños y } \\
\text { medianos }\end{array}$ & Sin datos & $\begin{array}{l}\text { Propietarios, } \\
\text { agencias } \\
\text { de viajes y } \\
\text { asociaciones }\end{array}$ & $\begin{array}{l}\text { Promoción del } \\
\text { producto } \\
\text { Programas } \\
\text { específicos } \\
\text { Capacitación }\end{array}$ \\
\hline Uruguay & 1980 & 100 & $\begin{array}{l}\text { Todos los } \\
\text { tamaños }\end{array}$ & $\begin{array}{l}\text { Cabalgatas y } \\
\text { gastronomía } \\
\text { típica }\end{array}$ & $\begin{array}{l}\text { Propietarios, } \\
\text { asociaciones, } \\
\text { Central de } \\
\text { reservas y } \\
\text { agencias de } \\
\text { viajes }\end{array}$ & $\begin{array}{l}\text { Promoción del } \\
\text { producto } \\
\text { Programas } \\
\text { específicos } \\
\text { Capacitación }\end{array}$ \\
\hline
\end{tabular}

Fuente: Elaborado a partir de OMT, 2003; Chavarría, 2009.

Nota: Debido a la carencia de datos específicos sobre las empresas de turismo rural en los países latinoamericanos, se utilizó la recopilación de ponencias realizada por el Representante Regional de las Américas de la OMT durante el Seminario Internacional sobre Turismo Rural y su contribución a la creación de empleo y a la conservación del patrimonio, llevado a cabo en Asunción, República del Paraguay, los días 12 y 13 de mayo de 2003, en el marco de la $40^{\circ}$ Reunión de la Comisión Regional para las Américas de la Organización Mundial del Turismo (OMT).

A partir de los años 70, surgen iniciativas de turismo rural en Nicaragua, Panamá y Argentina. Posteriormente, en los ochenta y noventa, se van sumando otros países a la oferta turística rural latinoamericana. Ejemplos de iniciativas de turismo rural en Latinoamérica son Baqueanos del Río, en Paraná, Argentina; la Asociación Artesanal Meri Sribire Guaire, en Panamá; el Albergue Rural Nicaragua Libre, en Nicaragua; la Asociación de Turismo Indígena Eco Red Lickan Antay, en Atacama, Chile; Albergue Ecológico Indígena San Miguel del Bala, en Bolivia; Asociación Ashaninka Napirori, en la comunidad Nativa San Miguel Centro Marankiari, en Perú, entre otras (Cañada, 2015).

Argentina, Chile y Brasil reportaron la mayor cantidad de establecimientos dedicados a esta actividad. Principalmente, se tratan de emprendimientos medianos o pequeños. Las actividades ofertadas son variables, cada comunidad ofrece experiencias auténticas 
y únicas que van desde cabalgatas, gastronomía, folclore, atractivos naturales, visita a haciendas, hasta la realización de tareas propias del medio rural. Los propietarios, las agencias de viajes o tour operadoras y las asociaciones son los encargados de la comercialización del producto. La mayoría de los países reciben apoyo gubernamental en áreas como promoción, programas específicos y capacitación. Únicamente Brasil, Chile, México y Panamá son apoyados por el sector público con financiamiento (tabla 2).

En las comunidades rurales indígenas latinoamericanas, las emprendedoras se organizan colectivamente a través del turismo rural cooperativo como una estrategia de lucha contra la pobreza, buscan el bien común, lo que a su vez contribuye a fortalecer su papel económico y social, permitiéndoles afrontar las desigualdades y discriminaciones a las que se han enfrentado continuamente (Galindo et al., 2016).

Las mujeres rurales inician su actividad emprendedora como solución a intentar combinar el cuidado de la familia con el trabajo (Pérez Galán, n.d.), complementar los ingresos del hogar (Pérez Galán, n.d.; Knight y Cottrell, 2016), mejorar su calidad de vida, pagar la educación a sus hijos (Knight y Cottrell, 2016), así como buscar el crecimiento personal y profesional (Ypeij, 2013). Estas emprendedoras se caracterizan por estar casadas, con hijos, tener entre 22 y 45 años, poseer baja escolaridad y combinar labores domésticas con la atención de los turistas (Morales Hernández et al., n.d.; Pérez Galán, n.d.).

Según investigaciones en países latinoamericanos como Chiloé (Chile) y Perú, las emprendedoras rurales también se enfrentan a la estacionalidad, la asignación de roles tradicionales de género (Morales Hernández et al., 2016; Pérez Galán, n.d.) y la explotación por parte de las empresas tour operadoras (Pérez Galán, n.d.). Sin embargo, las emprendedoras se agrupan y participan en proyectos de turismo rural comunitario que son desarrollados y/o apoyados por agencias de viajes, tour operadores y ONGs que actúan como comercializadores del producto turístico (Pérez Galán, n.d.; Ypeij, 2013; Knight y Cottrell, 2016).

Esta actividad económica, en continuo contacto con turistas permite a las mujeres mejorar su autoestima (Pérez Galán, n.d.; Knight y Cottrell, 2016), ser más felices y obtener el respeto de sus parejas (Knight y Cottrell, 2016). A través de estas actividades, las mujeres contribuyen al rescate de su identidad étnica, sus costumbres y tradiciones (Ypeij, 2013) y algunas se han convertido en líderes comunales que ayudan a otras a iniciar sus empresas (Ypeij, 2013; Beltrán Bravo, 2014).

\subsection{Emprendedoras turísticas rurales en Costa Rica}

En el plan nacional de desarrollo turístico de Costa Rica se incluye el turismo rural como un nuevo producto turístico a potenciar para complementar los existentes (ICT, 2010). La oferta de turismo rural se encuentra estructurada en grupos organizados en asociaciones o cooperativas; en empresas desarrolladas en grandes fincas, que buscan diversificar la actividad agrícola mediante el agroturismo; y en empresas lideradas por pequeños productores o campesinos, que diversifican su actividad principal mediante proyectos turísticos, en algunos casos familiares (Morera, 2006; Chavarría, 2009). 
El Instituto Costarricense de Turismo (ICT), ente rector de la actividad turística del país, clasifica las actividades de turismo rural que obtienen declaratoria turística ${ }^{2}$ en posadas de turismo rural y rural comunitario, agencias de viajes receptivas especializas en ofertas rurales, fincas de actividades temáticas y servicios de alimentos y bebidas criollas o tradicionales (Asamblea Legislativa de la República de Costa Rica, 2009).

El elemento distintivo entre las empresas de turismo rural y de turismo rural comunitario es que, en estas últimas la población local participa a través de organizaciones de base, asociaciones o cooperativas, que son las que gestionan la actividad turística (Calderón Fallas, 2017).

La financiación de los proyectos de turismo rural proviene de fuentes diversas. La banca estatal y privada ofrece opciones como son los fondos del Sistema Banca para el Desarrollo (cuyos fondos provienen del Fideicomiso Nacional para el Desarrollo [Finade], del Fondo de Crédito para el Desarrollo[FCD] y del Fondo de Financiamiento para el Desarrollo [Fofide]), el Fondo para el desarrollo de las mipymes (FODEMIPYME) creado por la Ley N8262 de Fortalecimiento de las Pequeñas y Medianas Empresas y administrado por el Banco Popular y de Desarrollo Comunal (BPDC) y créditos para mipymes con condiciones especiales (MEIC e Instituto Nacional de Aprendizaje [INA], 2019). Por otra parte, los proyectos de turismo rural costarricenses se han beneficiado de fondos no reembolsables provenientes de la cooperación internacional y de organizaciones como el Programa de Pequeñas Donaciones del Programa de las Naciones Unidas para el Desarrollo (PPD-PNUD) y la Fundecooperación para el Desarrollo Sostenible ( Chavarría, 2009).

Algunos ejemplos de casos exitosos de emprendimientos de turismo rural son Casa Calateas, es una Posada Rural fundada en 1993, que pertenece a la Asociación de Agricultores de la Comunidad Carbón Dos de Cahuita, Talamanca; Casa de las Mujeres, se ubica en la comunidad de Yorkín ubicado en el territorio indígena Bribri, pertenece a la Asociación Indígena Stibrawpa y se fundó en 1985; Albergue Heliconias, en 1991, veinte tres familias locales formaron la Asociación Bijagüeña de Productores Agrícolas y ofrecen alojamiento en medio de una reserva privada de bosque lluvioso; Posada de Turismo Rural El Silencio, es un proyecto de la cooperativa COOPESILENCIO RL que opera desde 1998, entre otros (Quirós y Bonilla, 2015). La cuarta edición de la guía de turismo rural comunitario de Costa Rica contiene la descripción de la oferta de 50 empresas de turismo rural que operan en el país.

De acuerdo con Hernández (2016), las mujeres emprendedoras turísticas rurales costarricenses se caracterizan por tener educación formal limitada, muy pocas completaron o han cursado estudios de secundaria o universitarios.

Éstas inician sus actividades de turismo rural buscando tomar riesgos, aprender (Hernández, 2016), fortalecer su autoestima (Cardín Pedrosa y Álvarez López, 2012), realizar actividades diferentes a las tareas domésticas (Calderón Fallas, 2017), buscar nuevas fuentes de ingresos (Nel-Lo Andreu, 2008; Calderón Fallas, 2017), diversificar las actividades productivas y preservar la cultura (Nel-Lo Andreu, 2008). Igualmente se enfrentan a limitaciones como la falta de apoyo familiar (González Calvo y Espinoza Herrera, 2010;

2 La declaratoria turística es un reconocimiento que se otorga a las empresas que voluntariamente lo solicitan ante el ICT, después de cumplir con una serie de requisitos técnicos, económicos y legales. Su objetivo es garantizar la legalidad y calidad del producto turístico costarricense (Poder Ejecutivo, 2018). 
Hernández, 2016), la estacionalidad del turismo (Ferguson, 2010), la carencia de título de propiedad (Beltrán Bravo, 2014), el difícil acceso a financiamiento (González Calvo y Espinoza Herrera, 2010), la baja autoestima y la dificultad para equilibrar trabajo y familia, lo que va asociado a otra barrera que son los roles de género tradicionales (Hernández, 2016).

A pesar de los altibajos que sufren, actualmente las emprendedoras sirven de ejemplo para que otras mujeres comiencen sus propios negocios y se capaciten (Hernández, 2016; Calderón Fallas, 2017). Su participación como empresarias les ha permitido generar nuevas fuentes de empleo e ingresos en la comunidad (Calderón Fallas, 2017). Además, promueven la preservación y promoción de los recursos naturales y la difusión de la cultura (Hernández, 2016; Calderón Fallas, 2017).

Las mujeres se unen a través de cooperativas o asociaciones para ofrecer paquetes turísticos, lo que, les permite mejorar su competitividad (Calderón Fallas, 2017). Cuentan con el respaldo de redes y plataformas externas que les ayudan con fondos no reembolsables, les brindan asesorías para ejecutar sus proyectos y contribuyen a la venta y comercialización del producto turístico que ofrecen (Nel-Lo Andreu, 2008; Calderón Fallas, 2017).

El modelo de desarrollo turístico sostenible adoptado por el país ha permitido el empoderamiento de pequeñas y medianas empresas, de forma que éstas constituyen el 93,3\% del parque empresarial del país y aportan el 27,7\% del empleo (MEIC y Dirección General de Apoyo a la Mipyme, 2017). Esto ha representado una oportunidad para que las mujeres rurales puedan diversificar sus fuentes de ingresos y tener una salida para enfrentar su condición de pobreza.

Sin embargo, a pesar de la importancia de las pequeñas y medianas empresas para el desarrollo del país, y de que Costa Rica cuenta con las características adecuadas para fomentar su crecimiento (Ramírez Alfaro, 2010), actualmente, se carece de estadísticas que permitan cuantificar el número de mipymes turísticas rurales dirigidas por mujeres que existen, muchas de las cuales operan en la informalidad. Asimismo, las investigaciones empíricas en torno a estas emprendedoras y sus empresas son escasas, lo que dificulta la realización de un análisis detallado sobre sus características, su funcionamiento y sus niveles de rentabilidad.

\section{RESULTADOS Y DISCUSIÓN}

La participación de la mujer empresaria ha aumentado en los últimos años a nivel mundial, lo que promueve la dinamización de la economía de los países y el aumento de ingresos en las comunidades. El sector servicios, y en especial el turístico, es el que brinda mayores oportunidades para que las mujeres puedan desarrollar sus negocios ya que actualmente, el turismo es un importante generador de divisas y de empleos tanto directos como indirectos e inducidos. Es el caso del turismo rural, que ha surgido como una opción para poblaciones marginadas, entre ellas las mujeres e indígenas, que viven en espacios rurales y desean diversificar sus actividades productivas o iniciar una empresa.

El turismo en Latinoamérica y el Caribe sigue creciendo. En 2017, Argentina, Brasil y Chile lideraron las estadísticas de llegadas de turistas en América del Sur, mientras que 
en Centroamérica fueron Costa Rica y Panamá, y en el Caribe, República Dominicana y Puerto Rico. México destacó dentro de los diez principales destinos de llegadas turísticas internacionales. Asimismo, estos países están en los mejores puestos en el Índice de Competitividad en Viajes y Turismo de 2017. Y las principales cinco economías latinoamericanas que ofrecen facilidad para hacer negocios, según el reporte "Doing Business" del Banco Mundial son México, Chile, Puerto Rico, Colombia y Costa Rica.

A pesar de las estadísticas favorables, la región debe mejorar en seguridad, protección, infraestructura, regulaciones y facilidades para hacer negocios. Otro aspecto que requiere la atención es la generación de empleo; ya que, a pesar de que Brasil y Costa Rica presentan datos positivos de ingreso de turistas, también ostentan las tasas más altas de desempleo femenino, así como la existencia de una alta cantidad de población femenina en situaciones de pobreza y pobreza extrema en América Latina y El Caribe.

La revisión de la literatura muestra que existen más coincidencias que diferencias en el perfil, motivaciones y barreras que enfrentan las mujeres emprendedoras dedicadas a cualquier tipo de negocio, al emprendimiento turístico y al turismo rural, tanto a nivel mundial, latinoamericano y costarricense.

De acuerdo con la información presentada en la tabla 3 se concluye que, existen similitudes en la edad, tamaño de la empresa y sector económico en el que se desempeñan las emprendedoras de Latinoamérica, Costa Rica y el resto del mundo.

Tabla 3

COMPARACIÓN DE LAS MUJERES EMPRENDEDORAS

\begin{tabular}{|c|c|c|c|}
\hline & $\begin{array}{l}\text { Emprendedoras en el } \\
\text { resto del mundo }\end{array}$ & $\begin{array}{l}\text { Emprendedoras en } \\
\text { Latinoamérica }\end{array}$ & $\begin{array}{l}\text { Emprendedoras en } \\
\text { Costa Rica }\end{array}$ \\
\hline Características & $\begin{array}{l}\text { Entre } 30 \text { y } 50 \text { años. } \\
\text { Educación universitaria } \\
\text { Utilizan ahorros personales. } \\
\text { Propietarias únicas. } \\
\text { Microempresas. } \\
\text { Menos de } 10 \text { empleados. } \\
\text { Sector servicios. }\end{array}$ & $\begin{array}{l}\text { Mediana edad. } \\
\text { Nivel educativo bajo. } \\
\text { Apoyo económico de } \\
\text { padres. } \\
\text { Micro y pequeñas } \\
\text { empresas. } \\
\text { Sector comercio, } \\
\text { servicios y } \\
\text { manufacturero. }\end{array}$ & $\begin{array}{l}\text { Entre } 35 \text { y } 49 \text { años. } \\
\text { Estudios universitarios. } \\
\text { Financian con ingresos } \\
\text { propios. } \\
\text { Inician empresa } \\
\text { con otras personas } \\
\text { (cónyuge, padres u otros } \\
\text { familiares). } \\
\text { Microempresas. } \\
\text { Sector servicios. }\end{array}$ \\
\hline Motivaciones & $\begin{array}{l}\text { Mejorar calidad de vida. } \\
\text { Deseo de independencia y } \\
\text { flexibilidad. } \\
\text { Generar ingresos. } \\
\text { Necesidad de satisfacción } \\
\text { laboral. }\end{array}$ & $\begin{array}{l}\text { Mejorar calidad de } \\
\text { vida. } \\
\text { Búsqueda de } \\
\text { flexibilidad e } \\
\text { independencia. } \\
\text { Necesidad de llevar } \\
\text { sustento a hogares. } \\
\text { Falta de oportunidades } \\
\text { en mercado laboral. }\end{array}$ & $\begin{array}{l}\text { Mejorar calidad de vida. } \\
\text { Necesidad de } \\
\text { independencia. } \\
\text { Apoyar económicamente } \\
\text { a familia. } \\
\text { Deseos de superación y } \\
\text { de emprender negocio. }\end{array}$ \\
\hline
\end{tabular}




\begin{tabular}{|c|c|c|c|}
\hline & $\begin{array}{l}\text { Emprendedoras en el } \\
\text { resto del mundo }\end{array}$ & $\begin{array}{l}\text { Emprendedoras en } \\
\text { Latinoamérica }\end{array}$ & $\begin{array}{l}\text { Emprendedoras en } \\
\text { Costa Rica }\end{array}$ \\
\hline Barreras & $\begin{array}{l}\text { Acceso a financiamiento. } \\
\text { Carencia de experiencia y } \\
\text { capacitación. } \\
\text { Desconocimiento para } \\
\text { redactar plan de negocios. } \\
\text { Falta de confianza. } \\
\text { Excesivas regulaciones } \\
\text { gubernamentales. }\end{array}$ & $\begin{array}{l}\text { Acceso a } \\
\text { financiamiento, } \\
\text { tecnología, } \\
\text { información y a redes } \\
\text { de comercialización. } \\
\text { Carencias en } \\
\text { formación y } \\
\text { experiencia } \\
\text { empresarial. } \\
\text { Excesiva tramitología. } \\
\text { Altos costos para } \\
\text { iniciar negocio. } \\
\text { Posee capital limitado. } \\
\text { Dificultades en } \\
\text { conciliar familia y } \\
\text { empresa. } \\
\text { No poseen título de } \\
\text { propiedad de activos } \\
\text { inmuebles o poseen } \\
\text { uno de bajo valor. }\end{array}$ & $\begin{array}{l}\text { Acceso a financiamiento. } \\
\text { Poca experiencia } \\
\text { y conocimiento } \\
\text { empresarial. } \\
\text { Falta de local comercial. }\end{array}$ \\
\hline
\end{tabular}

Estas emprendedoras se encuentran en un rango de edad entre 30 y 50 años, poseen microempresas y operan en el sector servicios. No obstante, se aprecian diferencias en cuanto a educación y forma de financiamiento de las empresarias latinoamericanas con respecto a las de Costa Rica y el resto del mundo, ya que las primeras poseen nivel educativo bajo y requirieron apoyo económico de los padres para iniciar, comparado con la posesión de estudios universitarios y la utilización de recursos propios para empezar la empresa de las últimas. Esto se puede atribuir a que tanto en Costa Rica como en países del resto del mundo se ofrecen condiciones propicias para estimular a las emprendedoras, mientras que en Latinoamérica las mujeres enfrentan menores oportunidades económicas, poseen un capital limitado y se requiere mayor apoyo gubernamental.

Las mujeres de las tres áreas geográficas analizadas comparten las mismas razones para emprender como son desear ser independientes, generar ingresos y mejorar su calidad de vida. Igualmente, las barreras que enfrentan estas emprendedoras son semejantes, ya que todas tienen dificultades para conseguir financiamiento y carecen de experiencia y capacitación en gestión empresarial. La burocracia se plantea como un obstáculo al emprendimiento también, aunque afecta tanto a hombres como a mujeres emprendedoras. 
Tabla 4

COMPARACIÓN DE LAS MUJERES EMPRENDEDORAS EN TURISMO

\begin{tabular}{|c|c|c|c|}
\hline & $\begin{array}{l}\text { Emprendedoras } \\
\text { turísticas } \\
\text { en el resto del mundo }\end{array}$ & $\begin{array}{l}\text { Emprendedoras } \\
\text { turísticas } \\
\text { en Latinoamérica }\end{array}$ & $\begin{array}{l}\text { Emprendedoras } \\
\text { turísticas } \\
\text { en Costa Rica }\end{array}$ \\
\hline Características & $\begin{array}{l}\text { De } 31 \text { a } 35 \text { años. } \\
\text { Casadas. } \\
\text { Con hijos. } \\
3 \text { y } 19 \text { empleados. } \\
\text { Educación secundaria y } \\
\text { universitaria. } \\
\text { Utilizaron ahorros } \\
\text { personales. } \\
\text { Consultan a familia para } \\
\text { tomar decisiones. }\end{array}$ & $\begin{array}{l}\text { Entre } 34 \text { a } 49 \text { años. } \\
\text { Casadas. } \\
\text { Tienen hijos. } \\
1 \text { a } 13 \text { empleados. } \\
\text { Educación superior. } \\
\text { Utilizó sus ahorros. } \\
\text { Actividades: hostelería } \\
\text { y agencias de viajes. } \\
\text { Recibieron capacitación } \\
\text { en turismo. } \\
\text { Empresas pequeñas. }\end{array}$ & $\begin{array}{l}\text { Promedio } 37 \text { años. } \\
\text { Casadas. } \\
\text { Tienen hijos. } \\
\text { Educación primaria } \\
\text { completa. } \\
\text { Dependen } \\
\text { económicamente del } \\
\text { padre o esposo. }\end{array}$ \\
\hline Motivaciones & $\begin{array}{l}\text { Necesidad y oportunidad. } \\
\text { Flexibilidad para combinar } \\
\text { trabajo y familia. } \\
\text { Mejorar autoestima. } \\
\text { Tener mayor confianza. } \\
\text { Obtener respeto de pareja } \\
\text { y comunidad. }\end{array}$ & 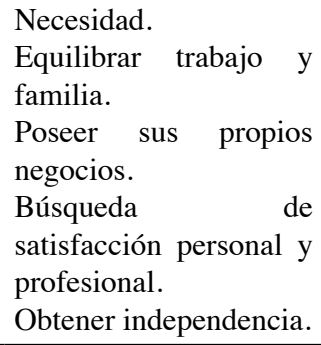 & $\begin{array}{l}\text { Razones económicas. } \\
\text { Forma de } \\
\text { entretenimiento. } \\
\text { Búsqueda de } \\
\text { autonomía. }\end{array}$ \\
\hline Barreras & $\begin{array}{l}\text { Falta de capital financiero. } \\
\text { Pertenecen al sector } \\
\text { informal. } \\
\text { Inexperiencia para } \\
\text { establecer redes } \\
\text { comerciales. } \\
\text { Asumir las tareas del } \\
\text { hogar. } \\
\text { Carencia de habilidades en } \\
\text { turismo. } \\
\text { Desconocimiento para } \\
\text { obtener financiación. } \\
\text { Venta de artesanías a } \\
\text { precios bajos. } \\
\text { Relaciones de poder. } \\
\text { Incapacidad de satisfacer, } \\
\text { en capacidad y en calidad, } \\
\text { demanda de productos } \\
\text { para complejos turísticos. } \\
\text { No apoyo de la pareja. }\end{array}$ & $\begin{array}{l}\text { Acceso a financiación. } \\
\text { Operan en la } \\
\text { informalidad. } \\
\text { Dificultad para creación } \\
\text { de redes, para conciliar } \\
\text { trabajo y familia. } \\
\text { Falta de capacitación. } \\
\text { Miedo al fracaso. } \\
\text { Falta de confianza para } \\
\text { iniciar. } \\
\text { Títulos de propiedad a } \\
\text { nombre de la pareja o } \\
\text { miembro de la familia } \\
\text { del hombre. }\end{array}$ & $\begin{array}{l}\text { Falta de confianza. } \\
\text { Títulos de propiedad } \\
\text { a nombre de pareja o } \\
\text { miembro de familia } \\
\text { del hombre. } \\
\text { Operan en la } \\
\text { informalidad. }\end{array}$ \\
\hline
\end{tabular}


Las empresarias turísticas poseen en general un mayor nivel educativo en Latinoamérica (ver Tabla 4), incluso, según los artículos revisados, recibieron capacitación en temas turísticos, mientras para Costa Rica poseen primaria. Tanto en el resto del mundo como en Latinoamérica, las mujeres poseen micro o pequeñas empresas, con menos de 19 empleados y usaron sus ahorros para iniciar el negocio.

Las razones por las que las mujeres emprendedoras en turismo deciden iniciar una empresa, son la necesidad, es decir, motivos económicos, así como la búsqueda de autonomía e independencia y la satisfacción personal. Tanto a escala global como en Latinoamérica, destaca la búsqueda de flexibilidad para combinar trabajo y familia. Las emprendedoras turísticas costarricenses fueron las únicas que señalaron que no consideran el emprendimiento como una obligación, lo ven como una forma de entretenimiento que les brinda autonomía, reconocimiento y les permite mejorar su calidad de vida. Esto se debe a que se reúnen para trabajar en sus artesanías con otras emprendedoras, convirtiendo las horas de trabajo en una alternativa de ocio, al tiempo que se fortalecen rompiendo las estructuras tradicionales del patriarcado.

Las emprendedoras turísticas en Centroamérica (tanto costarricenses como una parte de latinoamericanas), se caracterizan por la falta de confianza al iniciar sus empresas y la carencia de títulos de propiedad para la búsqueda de financiación. Por lo que se refiere a la mujer emprendedora turística rural, la información relativa a Latinoamérica y Costa Rica es escasa, por lo que se dificulta efectuar una comparación (ver Tabla 5). La única confrontación que se puede realizar de las características entre las empresarias en ambas regiones es que poseen baja escolaridad. Esto puede deberse a las condiciones de pobreza en las zonas rurales y la falta de oportunidades.

\section{Tabla 5}

\section{COMPARACIÓN DE LAS MUJERES EMPRENDEDORAS EN TURISMO RURAL}

\begin{tabular}{|c|c|c|c|}
\hline & $\begin{array}{l}\text { Emprendedoras } \\
\text { turísticas rurales } \\
\text { en el resto del mundo }\end{array}$ & $\begin{array}{l}\text { Emprendedoras } \\
\text { turísticas rurales } \\
\text { en Latinoamérica } \\
\end{array}$ & $\begin{array}{l}\text { Emprendedoras } \\
\text { turísticas rurales } \\
\text { en Costa Rica }\end{array}$ \\
\hline Características & $\begin{array}{l}\text { Mayor de } 36 \text { años. } \\
\text { Casadas. } \\
\text { Con hijos. } \\
\text { Estudios medios y } \\
\text { superiores. } \\
\text { Usa financiación ajena o } \\
\text { fondos propios. } \\
\text { Dependen de ingresos } \\
\text { del emprendimiento. } \\
\text { Microempresas. } \\
\text { Menos de } 5 \text { empleados. } \\
\text { Empleo no agrícola antes } \\
\text { de ser empresarias }\end{array}$ & $\begin{array}{l}\text { Entre } 22 \text { y } 45 \text { años. } \\
\text { Casadas. } \\
\text { Con hijos. } \\
\text { Baja escolaridad. } \\
\text { Combinan labores } \\
\text { Capacitación en turismo } \\
\text { y servicio al cliente. }\end{array}$ & $\begin{array}{l}\text { Educación formal } \\
\text { limitada. } \\
\text { domésticas con atención } \\
\text { de turistas. }\end{array}$ \\
\hline
\end{tabular}




\begin{tabular}{|c|c|c|c|}
\hline & $\begin{array}{l}\text { Emprendedoras } \\
\text { turísticas rurales } \\
\text { en el resto del mundo }\end{array}$ & $\begin{array}{l}\text { Emprendedoras } \\
\text { turísticas rurales } \\
\text { en Latinoamérica } \\
\end{array}$ & $\begin{array}{l}\text { Emprendedoras } \\
\text { turísticas rurales } \\
\text { en Costa Rica } \\
\end{array}$ \\
\hline Características & $\begin{array}{l}\text { Microempresas. } \\
\text { Menos de } 5 \text { empleados. } \\
\text { Empleo no agrícola antes } \\
\text { de ser empresarias. }\end{array}$ & & \\
\hline Motivaciones & $\begin{array}{l}\text { Combinar trabajo con } \\
\text { cuido de hijos. } \\
\text { Complementar ingresos. } \\
\text { Independencia. } \\
\text { Cambiar sus vidas. } \\
\text { Desarrollar ideas. } \\
\text { Poseer negocio propio. } \\
\text { Mantener la granja. } \\
\text { Conservar paisaje rural. } \\
\text { Trabajo menos solitario. }\end{array}$ & $\begin{array}{l}\text { Combinar cuido de } \\
\text { familia con trabajo. } \\
\text { Complementar ingresos. } \\
\text { Crecimiento personal y } \\
\text { profesional. } \\
\text { Mejorar calidad de vida. } \\
\text { Pagar educación de hijos. }\end{array}$ & $\begin{array}{l}\text { Nuevas fuentes de } \\
\text { ingresos. } \\
\text { Fortalecer autoestima. } \\
\text { Aprender y tomar } \\
\text { riesgos. } \\
\text { Realizar actividades } \\
\text { diferentes a las } \\
\text { domésticas. } \\
\text { Diversificar actividades } \\
\text { productivas. } \\
\text { Preservar la cultura. }\end{array}$ \\
\hline Barreras & $\begin{array}{l}\text { Estacionalidad del } \\
\text { turismo. } \\
\text { Estereotipo del rol de la } \\
\text { mujer tradicional. } \\
\text { Exclusión social. } \\
\text { Poco apoyo familiar. } \\
\text { Falta de confianza antes } \\
\text { de iniciar. } \\
\text { Altos costos para } \\
\text { emprender. } \\
\text { Tamaño pequeño de las } \\
\text { empresas. } \\
\text { Ausencia de experiencia } \\
\text { empresarial. }\end{array}$ & $\begin{array}{l}\text { Estacionalidad de la } \\
\text { actividad. } \\
\text { Roles tradicionales de } \\
\text { género. } \\
\text { Infravaloración del } \\
\text { trabajo femenino. } \\
\text { Explotación por } \\
\text { empresas tour } \\
\text { operadoras. }\end{array}$ & $\begin{array}{l}\text { Estacionalidad del } \\
\text { turismo. } \\
\text { Roles de género } \\
\text { tradicionales. } \\
\text { Falta de apoyo familiar. } \\
\text { Baja autoestima. } \\
\text { Acceso a financiamiento. } \\
\text { Equilibrio trabajo y } \\
\text { familia. } \\
\text { Carencia de título de } \\
\text { propiedad. }\end{array}$ \\
\hline
\end{tabular}

Las empresarias turísticas rurales a distintas escalas coinciden en estar casadas y tener hijos. Como las actividades turísticas en los países desarrollados son diferentes a las realizadas en los países en vías de desarrollo, las emprendedoras turísticas rurales en Latinoamérica presentan niveles educativos inferiores. Todas ellas, incluidas las costarricenses están motivadas por la necesidad de tener nuevas fuentes de ingresos y la búsqueda de crecimiento personal y profesional que les permita mejorar su calidad de vida.

Todas las emprendedoras turísticas rurales se enfrentan al obstáculo de la estacionalidad del turismo, debido a la marcada diferencia en la llegada de turistas entre la temporada alta (diciembre a abril y julio a agosto) y la temporada baja (mayo a junio y setiembre a noviembre), estos últimos meses coinciden con la época lluviosa, por tanto, viven en un marco de inestabilidad económica. A las empresarias se les continúan asignando los roles de género tradicionales como cocinar y limpiar, lo que implica que estas emprendedoras se enfrentan habitualmente a barreras como la falta de apoyo familiar y falta de confianza. 
Se debe agregar que existe una contrariedad en cuanto a que las mujeres emprendedoras en el turismo rural costarricenses señalan la dificultad para equilibrar trabajo y familia como una barrera mientras que Latinoamérica y el resto del mundo, lo incluyen como una motivación. Esta dificultad procede de la falta de apoyo de sus parejas, con mentalidad machista, y consideran que ellas deben encargarse del cuidado de los niños y de las tareas del hogar.

\section{CONCLUSIONES Y REFLEXIONES FINALES}

El análisis de la literatura e investigaciones sobre emprendedoras en el sector turístico rural en Costa Rica, a partir de la amplia revisión de la literatura en el tema, pone de manifiesto algunas conclusiones muy relevantes tanto para las emprendedoras como para los organismos encargados de su promoción.

Costa Rica se ha posicionado a nivel mundial con una imagen de destino turístico sostenible y a diferencia del resto de países centroamericanos, con excepción de Panamá, destaca por su competitividad turística y por brindar facilidad para hacer negocios.

A pesar de que el desarrollo del turismo rural en Costa Rica es menor con respecto a países como Argentina, Chile, Brasil o México; en el país se ha reconocido su importancia como un producto turístico que complementa los existentes y se ha ido consolidando una oferta turística rural variada.

Las emprendedoras turísticas rurales en Costa Rica parecen mostrar un nivel educativo inferior al del resto del ecosistema femenino emprendedor en el país. Las motivaciones para emprender de estas mujeres incluyen la posibilidad de tener una vida mejor al poder generar sus propios ingresos, pero también la voluntad de querer mantener y mostrar su estilo de vida, vinculado a las raíces culturales costarricenses. Acorde con las ideas de preservación del medio ambiente que han posicionado a Costa Rica como uno de los principales receptores de turismo sostenible, estas emprendedoras crean sus empresas intentando no variar sus tradiciones y mostrándoselas al turista.

La revisión de la literatura revela cómo las mujeres emprendedoras comparten muchos rasgos en todo el mundo. Entre ellos destaca el limitado acceso a la financiación, la informalidad y la necesidad de combinar de manera más flexible la vida familiar con la profesional. Los beneficios del emprendimiento femenino se dividen en dos aspectos. Por un lado, en la mejora de la calidad de vida de la familia por el aumento del ingreso familiar, y, por otro, las ventajas procedentes del empoderamiento de la mujer a través de la creación de su empresa. Estos dos efectos se refuerzan entre sí a lo largo del proceso emprendedor, multiplicando el potencial de crecimiento de sus empresas y el macroeconómico.

En el caso del turismo rural costarricense, estas mujeres se enfrentan a importantes limitaciones comparadas con el resto de las emprendedoras. Al tratarse de un entorno rural, las posibilidades ofrecidas por el mercado de trabajo son limitadas y las condiciones familiares no permiten a estas mujeres trabajar muy lejos de sus hogares. De esta manera, la creación de empresas dentro de su entorno les permite tener su propio trabajo y generar mejores condiciones de vida alrededor de su hogar. El vínculo de estas emprendedoras con las tradiciones y la cultura de su país hace que los beneficios del emprendimiento se amplíen. La posibilidad de crear un modo de vida sostenible, combinado con el orgullo y 
conocimiento del entorno, aumenta la capacidad de agencia, de empoderamiento y confianza en sí mismas de estas mujeres. Esta estrategia empresarial, aunque inicialmente de limitado crecimiento, se presenta como ideal para estas mujeres y el desarrollo económico de estas regiones en Costa Rica.

Sin embargo, esta investigación no está exenta de limitaciones, que, desde nuestra perspectiva, se convierten en oportunidades futuras. De alguna manera, la mayoría de los estudios encontrados se refieren a emprendimientos en países desarrollados.

Aún hay una escasez de información sobre la temática de la mujer emprendedora en el turismo rural, especialmente en América Latina y en Costa Rica. La falta de investigaciones empíricas y censos actualizados dificultan la realización de un análisis más detallado de la situación real de estas mujeres. Es necesario conocer más de las mujeres emprendedoras, sus características, sus fortalezas, sus debilidades, para que se dirijan políticas, programas y proyectos que incentiven su participación, su formación empresarial, faciliten el acceso al crédito y se fomente el crecimiento de sus empresas.

La escasez de información y estudios disponible pone de manifiesto la dificultad y la potencial necesidad de disponer de información primaria que permita conocer la situación de las empresarias y de sus empresas, así como establecer cuáles son los factores de éxito y fracaso al emprender en el sector turístico rural. Con ello se podrían realizar aportes relevantes para los tomadores de decisiones, que permitan robustecer la actividad emprendedora femenina, dada la importancia de las contribuciones de ésta para el desarrollo económico y social de las comunidades.

\section{REFERENCIAS}

ÁCS, Z.J., SZERB, L. y LLOYD, A. (2017): Global Entrepreneurship Index 2018. Washington, DC: The Global Entrepreneurship and Development Institute. Disponible en https://thegedi.org/2018-global-entrepreneurship-index/ (Accedido: 26 de octubre de 2018)

ADAMSON BADILLA, M., ESPINOZA CORRALES, D., HERRERA GONZÁLEZ, R. y VARELA MONTERO, L. (2016): Determining factors of entrepreneursip in Costa Rica: an econometric approach, documento de trabajo [DT_011_2016], Instituto de Investigaciones en Ciencias Económicas, Universidad de Costa Rica, Enero. Disponible en http://www.iice.ucr.ac.cr/documentos_trabajo/Determining\%20factors.pdf (Accedido: 29 marzo 2017)

ALM, E. y JOHANSSON, S. (2011): Women in tourism. Challenges of including women in the Maldivian Resort Sector, [en línea] Trabajo Fin de Máster. Lund University. Disponible en http://lup.lub.lu.se/student-papers/record/1967583 (Accedido: 10 julio 2017)

ASAMBLEA LEGISLATIVA DE LA REPÚBLICA DE COSTA RICA. (2002): «Ley de Fortalecimiento de las Pequeñas y Medianas Empresas», Diario Oficial La Gaceta, 17 de mayo del 2002 (8262), pp. 1-16. Disponible en http://reventazon.meic.go.cr/ informacion/legislacion/pyme/8262.pdf (Accedido: 12 enero 2018)

ASAMBLEA LEGISLATIVA DE LA REPÚBLICA DE COSTA RICA. (2009): «Ley Fomento del Turismo Rural Comunitario», Diario Oficial La Gaceta, 01 de octubre del 2009 (8724), pp. 1-6. Disponible en http://www.ict.go.cr/es/documentos-institu- 
cionales/legislación-de-empresas/leyes-y-reglamentos/630-ley-fomento-del-turismorural-comunitario/file.html (Accedido: 25 enero 2018)

ASCHER, J. (2012): «Female Entrepreneurship - An appropriate response to gender discrimination», Journal of Entrepreneurship, Management and Innovation, vol. 8 (4), pp. 97-114.

AYADURAI, S. y SOHAIL, M.S. (2006): «Profile of women entrepreneurs in a war-torn area: case study of north east Sri Lanka», Journal of Developmental Entrepreneurship, vol. 11 (1), pp. 3-17.

BANCO CENTRAL DE COSTA RICA (BCCR). (2018): Cuenta Satélite de Turismo 2016. San José: Departamento de Estadística Macroeconómica. Disponible en https:// www.bccr.fi.cr/seccion-indicadores-economicos/cuenta-sat\%C3\%A9lite-de-turismo (Accedido: 16 noviembre 2018)

BANCO MUNDIAL. (2015): Latinomérica Indígena en el Siglo XXI. Washington, D.C.: Banco Mundial. Licencia: Creative Commons de Reconocimiento CC BY 3.0 IGO. Disponible en http://documents.worldbank.org/curated/en/541651467999959129/ pdf/98544-WP-P148348-Box394854B-PUBLIC-Latinoamerica-indigena-SPANISH. pdf (Accedido: 6 de setiembre de 2019)

BANCO MUNDIAL. (2018): Doing Business 2019. 16 th $^{\text {th }}$. Wasinhgton D.C.: International Bank for Reconstruction and Development / The World Bank. Disponible en http://www.worldbank.org/content/dam/doingBusiness/media/Annual-Reports/ English/DB2019-report_web-version.pdf (Accedido: 2 de noviembre de 2018)

BELTRÁN BRAVO, L.R. (2014): Sistematización de tres experiencias de jóvenes que migraron a la ciudad y retornaron al campo. Puno, Perú. Disponible en http://juventudruralemprendedora.procasur.org/wp-content/uploads/2015/06/Jovenes-retornadosFINAL.pdf (Accedido: 6 setiembre 2017)

BONILLA MOYA, M. (2002): Fortalecimiento del ocio de mujeres que trabajan en turismo rural: estudio del caso de Monteverde, Costa Rica, Documentos de Estudios de Ocio, (19), pp. 151-168. Bilbao: Universidad de Deusto. Disponible en http://www. deusto-publicaciones.es/deusto/pdfs/ocio/ocio19.pdf (Accedido: 23 mayo 2017)

BRENES BONILLA, L. y BERMÚDEZ MESÉN, L. (2013): «Diferencias por género en el emprendimiento empresarial costarricense», TEC Empresarial, vol.7 (2), pp. 19-27.

BRUSH, C.G., DE BRUIN, A. y WELTER, F. (2009): «A gender $\square$ aware framework for women's entrepreneurship», International Journal of Gender and Entrepreneurship, vol. 1 (1), pp. 8-24.

BUTTNER, E.H. (1993): «Female Entrepreneurs: how far have they come?», Business Horizons, vol. 36 (2), pp. 59-65.

CAF-BANCO DE DESARROLLO DE AMÉRICA LATINA. (2013): Emprendimientos en América Latina desde la Subsistencia hacia la Transformación Productiva. Bogotá, Colombia: CAF. Disponible en http://publicaciones.caf.com/media/33191/red_2013. pdf (Accedido: 12 noviembre 2018)

CALDERÓN FALLAS, E.G. (2017): «Turismo rural comunitario, agricultura familiar y desarrollo rural. Análisis de algunas experiencias en las áreas rurales de Costa Rica», Revista Española de estudios agrosociales y pesqueros, $\mathrm{n}^{\circ} 247 . \mathrm{pp} .15-58$. 
CAÑADA, E. (2005): Catálogo Latinoamericano de Turismo Rural Comunitario. Barcelona, Alba Sud Editorial. Disponible en http://www.albasud.org/publicacion/es/70/ catalogo-latinoamericano-de-turismo-rural-comunitario (Accedido: 10 setiembre 2019)

CARDÍN PEDROSA, M. y ÁLVAREZ LÓPEZ, C.J. (2012): «El Turismo Rural Comunitario en Costa Rica», en XI Congreso Internacional de Ingeniería de Proyectos, 26-28 Setiembre 2007, Lugo. Disponible en http://www.aeipro.com/files/congresos/2007lugo/ ciip07_1658_1666.340.pdf (Accedido: 5 noviembre 2018)

CHAVARRÍA, C.R. (2009): Estudio sobre turismo rural en Costa Rica, documento de trabajo, Instituto Interamericano de Cooperación para la Agricultura, San José, Costa Rica, Febrero. Disponible en http://legacy.iica.int/Esp/organizacion/LTGC/agroturismo/Documentos Agroturismo/Forms/AllItems.aspx (Accedido: 24 enero 2018)

COMISIÓN ECONÓMICA PARA AMÉRICA LATINA Y EL CARIBE (CEPAL) (2017): Anuario Estadístico de América Latina y el Caribe 2017. (LC/PUB.2018/2-P). Santiago: Naciones Unidas. Naciones Unidas. Disponible en https://www.cepal.org/es/ publicaciones/43239-anuario-estadistico-america-latina-caribe-2017-statistical-yearbook-latin (Accedido: 5 noviembre 2018)

CEPAL. (2018): Estadísticas e indicadores. Disponible en http://estadisticas.cepal.org/ cepalstat/web_cepalstat/estadisticasindicadores.asp (Accedido: 26 noviembre 2018)

COSTA, C., BREDA, Z., BAKAS, F.E., DURÃO, M. y PINHO, I. (2015): «Profiling the contemporary brazilian tourism entrepreneur : a gender analysis», Journal of Women's Entrepreneurship and Education, vol. 3 (4), pp. 1-27.

COSTA, C., BREDA, Z., BAKAS, F.E., DUR ̃̃O, M. y PINHO, I. (2016): «Through the gender looking-glass: Brazilian tourism entrepreneurs», International Journal of Gender and Entrepreneurship, vol. 8 (3), pp. 282-306.

DEMARTINO, R. y BARBATO, R. (2003): «Differences between women and men MBA entrepreneurs: exploring family flexibility and wealth creation as career motivators», Journal of Business Venturing, vol. 18 (6), pp. 815-832.

DÍAZ CASERO, J.C., HERNÁNDEZ MOGOLLÓN, R., SÁNCHEZ ESCOBEDO, M.C. y POSTIGO JIMÉNEZ, M.V. (2010): «Actividad emprendedora y género. Un estudio comparativo», Revista Europea de Dirección y Economía de la Empresa, vol. 19 (2), pp. 83-98.

FERGUSON, L. (2010): Tourism as a development strategy in Central America: exploring the impact on women's lives, documento informativo, Central America women's network, Marzo. Disponible en http://cawn.org/assets/Tourism as a development strategyFINAL.pdf (Accedido: 6 setiembre 2017)

FERNÁNDEZ ALDECUA, M.J. y MARTÍNEZ BARÓN, L.A. (2010): «Participación de las mujeres en las empresas turísticas privadas y comunitarias de Bahías de Huatulco, México. ¿Hacia un cambio en el rol de género?», Cuadernos de Turismo, n 26, pp. 129-151.

FLORES, D. y BARROSO, M. DE LA O. (2011): «La mujer en el turismo rural: un análisis comparativo de género en el Parque Natural Sierra de Aracena y Picos de Aroche (comarca Noroccidental andaluza)», Ager. Revista de Estudios sobre Despoblación y Desarrollo Rural, n 10 , pp. 39-69. 
FORO ECONÓMICO MUNDIAL. (2017): The Travel \& Tourism Competitiveness Report 2017. Genova: Foro Económico Mundial. Disponible en: https:/www.weforum.org/ reports/the-travel-tourism-competitiveness-report-2017 (Accedido: 1 noviembre 2018)

GALINDO REYES, F.C, CIRUELA LORENZO, A.M., PÉREZ MORENO, S. y PÉREZ CANTO, S. (2016): «Rural indigenous women in Bolivia: A development proposal based on cooperativism». Women's Studies International Forum, vol. 59, pp. 58-66.

GARIN CONTRERAS, A. (2015): «Turismo rural en el acomuna de Villarica - Chile: institucionalidad y emprendedores rurales», Estudios y Perspectivas en Turismo, vol. 24 (1), pp. 21-39.

GONZÁLEZ CALVO, H. y ESPINOZA HERRERA, R. (2010): «Mujer, organización y promoción social: su participación como agente de cambio en la comunidad de Guatuso, Costa Rica», en Benavides Calvo, N. y Escalera Reyes, J. (Eds), Turismo sostenible, desarrollo local y articulación regional transfronteriza en el Río San Juan (Costa Rica-Nicaragua), Facultad Latinoamericana de Ciencias Sociales, San José, Costa Rica, pp. 205-235. Disponible en http://biblioteca.clacso.edu.ar/Costa_Rica/ flacso-cr/20170704043403/pdf_194.pdf (Accedido: 4 abril 2017)

GTZ, BANCO MUNDIAL y BANCO INTERAMERICANO DE DESARROLLO. (2010): Mujeres Empresarias: Barreras y Oportunidades en el Sector Privado Formal en América Latina, LEDEL SAC, Lima, Perú. Disponible en http://siteresources.worldbank. org/INTLACREGTOPPOVANA/Resources/840442-1260809819258/Libro_Mujeres_ Empresarias.pdf (Accedido: 25 marzo 2017)

HALL, G. y PATRINOS, H.A. (2005): «Los pueblos indígenas de América Latina». Finanzas \& Desarrollo, pp. 23-24. Disponible en https://www.imf.org/external/pubs/ $\mathrm{ft} /$ fandd/spa/2005/12/pdf/hall.pdf (Accedido: 5 de setiembre de 2019)

HELLER, L. (2010): Mujeres emprendedoras en América Latina y el Caribe: realidades, obstáculos y desafíos mujer y desarrollo. Serie mujer y desarrollo. Naciones Unidas, Santiago, Chile. Disponible en http://repositorio.cepal.org//handle/11362/5818 (Accedido: 6 marzo 2017)

HERNÁNDEZ, M.G. (2016): «Design research, storytelling, and entrepreneur women in rural Costa Rica: a case study», en Actas del DRS 2016, Design Research Society 50th Anniversary Conference, Brighton, UK, 27-30 June 2016, pp. 1-19. Disponible en http://www.drs2016.org/417/ (Accedido: 5 abril 2017)

INSTITUTO COSTARRICENSE DE TURISMO (ICT). (2010): Plan nacional de turismo sostenible de Costa Rica 2010-2016. Resumen Ejecutivo. San José, Costa Rica. Disponible en http://www.ict.go.cr/es/documentos-institucionales/plan-nacional-y-planesgenerales/plan-nacional-de-desarrollo.html (Accedido: 18 abril 2017)

ICT. (2015): «Impulso al crecimiento y desarrollo turístico en Costa Rica», en Vigesimoprimer Informe Estado de la Nacion en Desarrollo Humano Sostenible 2014. Disponible en http://estadonacion.or.cr/files/biblioteca_virtual/021/economia/ICTTurismoC3. pdf (Accedido: 26 abril 2017)

INSTITUTO NACIONAL DE ESTADÍSTICA Y CENSOS (INEC). (2016): Encuesta Nacional de Hogares Productores 2015. San José, Costa Rica: INEC. Disponible en http://www.inec.cr/sites/default/files/documetos-biblioteca-virtual/reenhopro2015.pdf (Accedido: 6 de setiembre de 2019) 
JASPERS, D. y MONTAÑO, S. (2013): Mujeres indígenas en América Latina: dinámicas demográficas y sociales en el marco de los derechos humanos. Documentos de proyectos $\mathrm{N}^{\circ} 558$. CEPAL y ONU Mujeres. Disponible en https://www.cepal.org/es/ publicaciones/4100-mujeres-indigenas-america-latina-dinamicas-demograficas-sociales-marco-derechos (Accedido: 11 de setiembre de 2019)

KATONGOLE, C., AHEBWA, W.M. y KAWERE, R. (2013): «Enterprise success and entrepreneur's personality traits: an analysis of micro- and small-scale women-owned enterprises in Uganda's tourism industry», Tourism and Hospitality Research, vol. 13 (3), pp. 166-177.

KELLEY, D., BRUSH, C., GREENE, P., HERRINGTON, M., ALI, A. y KEW, P. (2015): «GEM Special Report Women's Entrepreneuship 2014». Disponible en http://gemconsortium.org/report/49281 (Accedido: 3 marzo 2017)

KELLEY, D.J.; BAUMER, B.S.; BRUSH, C.; GREENE, P.G.; MAHDAVI, M.; MAJBOURI, M.; COLE, M., DEAN, M. y HEAVLOW, R. (2017): Global Entrepreneurship Monitor. Women's Entrepreneurship 2016/2017 Report. Disponible en https://www. gemconsortium.org/report/49860 (Accedido: 26 de octubre de 2018)

KNIGHT, D.W. y COTTRELL, S.P. (2016): «Evaluating tourism-linked empowerment in Cuzco, Peru», Annals of Tourism Research. vol. 56, pp. 32-47.

KOUTSOU, S., NOTTA, O., SAMATHRAKIS, V. y PARTALIDOU, M. (2009): «Women's entrepreneurship and rural tourism in Greece: private enterprises and cooperatives», South European Society and Politics, vol. 14 (2), pp. 191-209.

LEIVA BONILLA, J.C. (2013): «¿Quién crea mipymes en Costa Rica?», Tec Empresarial, $\mathrm{n}^{\circ}$, pp. 9-17.

LING, R.S.J., WU, B., PARK, J., SHU, H. y MORRISON, A.M. (2013): «Women's role in sustaining villages and rural tourism in China», Annals of Tourism Research, 43, pp. 634-638.

MASTERCARD. (2018): Index of Women Entrepreneurs 2018. Disponible en https:// newsroom.mastercard.com/wp-content/uploads/2018/03/MIWE_2018_Final_Report. pdf (Accedido: 9 setiembre 2019)

MCCLELLAND, E., SWAIL, J., BELL, J. y IBBOTSON, P. (2005): «Following the pathway of female entrepreneurs: A six $\square$ country investigation», International Journal of Entrepreneurial Behavior \& Research, vol. 11 (2), pp. 84-107.

MCGEHEE, N.G., KIM, K. y JENNINGS, G.R. (2007): «Gender and motivation for agritourism entrepreneurship», Tourism Management, vol. 28 (1), pp. 280-289.

MINISTERIO DE ECONOMÍA INDUSTRIA Y COMERCIO (MEIC) Y DIRECCIÓN GENERAL DE APOYO A LA MIPYME. (2017): Estado de situación de las PYME en Costa Rica 2016. San José, Costa Rica: MEIC.

MEIC E INSTITUTO NACIONAL DE APRENDIZAJE. (2019): Acceso a financiamiento. Disponible en https://www.pyme.go.cr/pymecr1.php?id=5 (Accedido: 10 setiembre 2019)

MEIC y ORGANIZACIÓN INTERNACIONAL DEL TRABAJO (OIT). (2019): Manual para las personas emprendedoras en Costa Rica. Disponible en https://www.meic. go.cr/meic/documentos/08k2mt84w/Manual_PersonasEmprendedorasCR300519.pdf (Accedido: 11 setiembre 2019) 
MORALES HERNÁNDEZ, A.M., FERNÁNDEZ HERNÁNDEZ, C. y DÍAZ PÉREZ, F.M. (2016): «Roles de género en turismo rural: ¿cambio o permanencia?», en XIX Congreso AECIT Tiempos de cambio en el turismo, 16-18 Noviembre 2016, Adeje, Tenerife. Disponible en https://www.aecit.org/files/congress/19/papers/282.pdf (Accedido: 24 febrero 2018)

MORERA, C. (2006): «Concepto y realidad del turismo rural en Costa Rica», Ambientico, March, pp. 4-8. Disponible en http://www.ambientico.una.ac.cr/pdfs/ambientico/150. pdf (Accedido: 23 enero 2018)

NEL-LO ANDREU, M. (2008): «Organización y características del turismo rural comunitario en Costa Rica», Anales de Geografía, vol. 28 (2), pp. 167-188. Disponible en http://revistas.ucm.es/index.php/AGUC/article/view/31987 (Accedido: 28 abril 2017)

ONU MUJERES. (2017): El progreso de las mujeres en América Latina y el Caribe 2017. Transformar las economías para realizar los derechos. Disponible en http://lac. unwomen.org/es/digiteca/publicaciones/2016/12/el-progreso-de-las-mujeres-americalatina-y-el-caribe-2017 (Accedido: 27 noviembre 2018)

ORGANIZACIÓN MUNDIAL DEL TURISMO (OMT) Y HUZHOU CITY. (2017): International Rural Tourism Development - An Asia-Pacific Perspective. Madrid. Disponible en https://doi.org/10.18111/9789284418824 (Accedido: 5 setiembre 2017)

OMT y ONU MUJERES. (2013): Informe mundial sobre las mujeres en el turismo 2010. Madrid, España. Disponible en https://www.e-unwto.org/doi/ pdf/10.18111/9789284414789 (Accedido: 13 febrero 2018)

OMT. (2002): Turismo: Panorama 2020. Volumen 7: Previsiones mundiales y perfiles de los segmentos de mercado. Madrid. Disponible en https://www.e-unwto.org/doi/ book/10.18111/9789284404766 (Accedido: 18 febrero 2018)

OMT. (2003): «El Turismo Rural en las Américas y su contribución a la creación de empleo y a la conservación del patrimonio», en Seminario Internacional sobre Turismo Rural y su contribución a la creación de empleo y a la conservación del patrimonio, Asunción, Paraguay, 12-13 mayo 2003, pp. 1-304. Disponible en https://www.e-unwto. org/doi/book/10.18111/9789284406630 (Accedido: 25 febrero 2018)

OMT. (2018): UNWTO Tourism Highlights: 2018 Edition. Disponible en https://www.eunwto.org/doi/book/10.18111/9789284419876 (Accedido: 13 noviembre 2018)

ORGANIZACIÓN PARA LA COOPERACIÓN Y EL DESARROLLO ECONÓMICOS (OCDE). (2018): Entrepreneurship at a Glance Highlights 2018. Disponible en http:// www.oecd.org/industry/business-stats/ (Accedido: 6 noviembre 2018)

PADILLA MELÉNDEZ, A. y CIRUELA-LORENZO, A.M. (2018): «Female indigenous entrepreneurs, culture and social capital. The case of the Quechua community of Tiquipaya (Bolivia)», Women's Studies International Forum, vol. 69, pp. 159-170.

PÉREZ GALÁN, B. (n.d.): «Turismo rural comunitario, género y desarrollo en Perú. La participación de las mujeres». Disponible en http://s0274b3d5d9ba961c.jimcontent. com/download/version/1415678015/module/8890510569/name/Turismo Rural Comunitario, Género y Desarrollo en Perú.pdf (Accedido: 3 setiembre 2017)

PÉREZ, S. (2010): «El valor estratégico del turismo rural como alternativa sostenible de desarrollo territorial rural», Agronomía Colombiana, vol. 28 (3), pp. 507-513. 
PETTERSSON, K. y HELDT CASSEL, S. (2014): «Women tourism entrepreneurs: doing gender on farms in Sweden», Gender in Management, vol. 29 (8), pp. 487-504.

PICÓN CRUZ, J.C. y HERNÁNDEZ ULATE, A. (2014): «El turismo rural comunitario en los procesos de la nueva ruralidad: la experiencia latinoamericana», en XVIII Congreso AECIT, Turismo: Liderazgo, Innovación y Emprendimiento, 26-28 noviembre 2014, INVAT·TUR, Benirdorm. Disponible en https://www.aecit.org/files/congress/18/ papers/42.docx (Accedido: 26 febrero 2018)

PODER EJECUTIVO. (2018): «Reglamento de las Empresas y Actividades Turísticas», Diario Oficial La Gaceta, 7 de diciembre del 2018 (228), Costa Rica, pp. 1-19. Disponible en https://www.ict.go.cr/es/documentos-institucionales/legislaci\%C3\%B3n-de-empresas/leyes-y-reglamentos/595-reglamento-de-las-empresas-y-actividades-turisticas-1/ file.html (Accedido: 10 setiembre 2019)

PROGRAMA ESTADO DE LA NACIÓN EN DESARROLLO HUMANO SOSTENIBLE (COSTA RICA). (2016): Vigesimosegundo Informe Estado de la Nación en Desarrollo Humano Sostenible. 22 ed. San José, C.R.: PEN. Disponible en https:// estadonacion.or.cr/informes/ (Accedido: 11 setiembre 2019)

QUADER, M.S. (2012): «A characteristic model of successful women entrepreneurs in the UK», Journal of Services Research, vol. 12 (1), pp. 89-113.

QUIRÓS, C. y BONILLA, M. (2015): «Costa Rica, Guía de Turismo Rural Comunitario». 4ta ed. San José, Costa Rica. Disponible en http://www.pequenasdonacionescr.org/ noticias/guia-de-turismo-rural-comunitario (Accedido: 10 setiembre 2019)

RAMADANI, V., REXHEPI, G., ABAZI-ALILI, H., BEQIRI, B. y THAÇI, A. (2015): «A look at female entrepreneurship in Kosovo: an exploratory study», Journal of Enterprising Communities, vol. 9 (3), pp. 277-294.

RAMÍREZ ALFARO, L. (2010). «La informalidad y semiformalidad empresarial en Costa Rica: Un acercamiento desde la mirada de personas expertas». San José, Costa Rica: Universidad Estatal a Distancia. Disponible en http://investiga.uned.ac.cr/omipymes/ wp-content/uploads/2013/12/Cuadernillo-5-Informalidad-y-semiformalidad-en-CostaRica.pdf (Accedido: 26 de mayo de 2016)

RATTEN, V. y DANA, L.P. (2017): «Gendered perspective of indigenous entrepreneurship». Small Enterprise Research, vol. 24 (1), pp. 62-72.

RUIZ NAVARRO, J., CAMELO ORDAZ, M.C. y CODURAS MARTÍNEZ, A. (2012): «Mujer y desafío emprendedor en España: características y determinantes», Economía Industrial, $\mathrm{n}^{\mathrm{o}}$ 383, pp. 13-22.

SARANGO LALANGUI, P., ARMAS HERRERA, R. y RAMÓN JARAMILLO, S.E. (2016): «Emprendimiento femenino y turismo religioso en Ecuador», en Rocha, A., Reis, L.P., Pérez Cota, M., Santana Suárez, O. y Gonçalves, R. (Eds), Actas 11a Conferencia Ibérica de Sistemas y Tecnologías de Información, Gran Canaria, España, 15-18 de Junio de 2016, pp. 433-438. Disponible en https://doi.org/10.1109/ CISTI.2016.7521637 (Accedido: 22 noviembre 2016)

SAARINEN, J. (2006): «Traditions of sustainability in tourism studies», Annals of Tourism Research, vol. 33 (4), pp. 1.121-1.140.

SISTEMA ECONÓMICO LATINOAMERICANO Y DEL CARIBE (SELA). (2010): Desarrollando mujeres empresarias: la necesidad de replantear políticas y programas de 
género en el desarrollo de PYMES, documento de trabajo [SP/Di No. 5-10], Secretaría Permanente del SELA, Caracas, Venezuela, Junio. Disponible en http://www.sela.org/ media/268540/desarrollando-mujeres-empresarias-pymes.pdf (Accedido: 6 marzo 2017)

STILL, L.V y WALKER, E.A. (2006): «The self-employed woman owner and her business: an australian profile», Women in Management Review, vol. 21 (4), pp. 294-310.

TAJEDDINI, K., RATTEN, V. y DENISA, M. (2017): «Female tourism entrepreneurs in Bali, Indonesia», Journal of Hospitality and Tourism Management, vol. 31, pp. 52-58. TALÓN BALLESTERO, P., ABAD ROMERO, P. y GONZÁLEZ SERRANO, L. (2014): «Emprendimiento de la mujer en el ámbito rural: el turismo como motor de desarrollo», Esic Market Economics and Business Journal, vol. 45 (3), pp. 579-604.

TRAVERSO CORTÉS, J., IRRIBARREN ALCAÍNO, L.A. y ROMÁN ONSALO, M. (2014): «Emprendimiento femenino y desempeño de las empresas en la República de Chile», en V Congreso Universitario Internacional Investigación y Género, Sevilla, 3-4 Julio 2014. Disponible en https://idus.us.es/xmlui/handle/11441/40955 (Accedido: 23 octubre 2016)

TSHABALALA, S.P. y EZEUDUJI, I.O. (2016): «Women tourism entrepreneurs in KwaZulu-Natal, South Africa : any way forward ?», Acta Universitatis Danubius. Oeconomica, vol. 12 (5), pp. 19-32.

WORLD TRAVEL \& TOURISM COUNCIL (WTTC). (2018a): Travel \& Tourism economic impact 2018 World. Disponible en https://www.wttc.org/economic-impact/ country-analysis/regional-reports/ (Accedido: 14 noviembre 2018)

WTTC. (2018b): «Travel \& Tourism economic impact 2018 Américas». Disponible en https://www.wttc.org/economic-impact/country-analysis/regional-reports/ (Accedido: 14 noviembre 2018)

WTTC. (2018c): Travel \& Tourism economic impact 2018 Costa Rica. Disponible en https://www.wttc.org/economic-impact/country-analysis/country-reports/ (Accedido: 14 noviembre 2018)

YPEIJ, A. (2013): «Cholos, incas y fusionistas: el nuevo Perú y la globalización de lo andino», Revista Europea de Estudios Latinoamericanos y del Caribe, (94), pp. 67-82.

ZAMBERI AHMAD, S. (2011): «Evidence of the characteristics of women entrepreneurs in the Kingdom of Saudi Arabia», International Journal of Gender and Entrepreneurship, vol. 3 (2), pp. 123-143.

ZAPALSKA, A. (1997): «A profile of woman entrepreneurs and enterprises in Poland», Journal of Small Business Management, vol. 35 (4), pp. 76-82. 